Manuscript submitted to the joint EAGE-SEG special issue on Hydrogeophysics

\title{
CHARACTERIZATION OF SEAWATER INTRUSION USING 2D ELECTRICAL IMAGING
}

\author{
F. NGUYEN*12, A. KEMNA ${ }^{13}$, A. ANTONSSON ${ }^{4}$, P. ENGESGAARD ${ }^{4}$, O. KURAS ${ }^{5}$, R. OGILVY ${ }^{5}, \mathrm{~J}$ GISBERT $^{6}, \mathrm{~S}$ \\ JORRETO $^{6}$, A. PULIDO-BOSCH ${ }^{6}$
}

\begin{abstract}
We have investigated the potential of 2D electrical imaging for the characterization of seawater intrusion using field data from a site in Almeria, SE Spain. Numerical simulations have been run for several scenarios, with a hydrogeological model reflecting the local site conditions. The simulations showed that only the lower salt concentrations of the seawater-freshwater transition zone could be recovered, due to the loss of resolution with depth. We quantified this capability in terms of the cumulative sensitivity associated with the measurement setup and showed that the mismatch between the targeted and imaged parameter values occurs from a certain sensitivity threshold. Similarly, heterogeneity may only be determined accurately if located in an adequately sensitive area. At the field site, we identified seawater intrusion at the scale of a few kilometres down to a hundred metres. Borehole logs show a remarkable correlation with the image obtained from surface data but indicate that the electrically derived mass fraction of pure seawater could not be recovered due to the discrepancy between the in-situ and laboratory-derived petrophysical relationships. Surface-to-hole inversion results suggest that the laterally varying resolution pattern associated with such a setup dominates the image characteristics compared to the laterally more homogeneous resolution pattern of surface only inversion results, and hence surface-to-hole images are not easily interpretable in terms of larger-scale features. Our results indicate that electrical imaging can be used to constrain seawater intrusion models if image appraisal tools are appropriately used to quantify the spatial variation of sensitivity and resolution. The most crucial limitation is probably the apparent non stationarity of the petrophysical relationship during the imaging process.
\end{abstract}

1 Agrosphere, ICG-4, Forschungszentrum Juelich GmbH, D-52425 Juelich, Germany

2 Now, Department of Architecture, Geology, Environment \& Constructions, University of Liège, Chemin des Chevreuils 1, 4000 Liège, Belgium

* Corresponding author

3 Now, Department of Geodynamics and Geophysics, University of Bonn, Nussallee 8, D-53115 Bonn, Germany

${ }^{4}$ Institute of Geology, University of Copenhagen, Oster Voldgade 10, DK-1210 Copenhagen K, Denmark

5 British Geological Survey, Keyworth, Nottingham, NG12 5GG, United Kingdom

${ }^{6}$ Department of Hydrogeology, University of Almeria, Campus Universitario, E-04120 Almeria, Spain E-mail address: f.nguyen@ulg.ac.be.

Key words and phrases. Electrical resistance tomography, saline intrusion, hydrogeophysics. 


\section{INTRODUCTION}

Seawater intrusion is a natural process occurring along shores and results from the interaction between sea water and coastal aquifers (figure 1a). The classic analytical description of Ghyben-Herzberg allows a quick understanding of the system: due to the fact that dissolved salts give sea water a greater density than fresh water, sea water flows inland in fresh water aquifers to form a wedge at equilibrium. The increasing development of coastal regions (Bear et al., 1999; Cheng and Ouazar, 2004), which generates higher water demands, and the sea-level rise due to climate changes (Melloul and Collin, 2006) stress such systems and contribute in migrating the intrusion further inland (figure 1b). The direct consequence of seawater intrusion is the degradation of water quality which becomes unsuitable for drinking or irrigation (Bear et al., 1999). In the longer term, coastal ecosystems (both marine and fresh), which are strongly affected by nutrients, contaminants and trace elements brought by submarine groundwater discharge (Michael et al., 2005), may also be affected by seawater intrusion dynamics. To manage or study efficiently seawater intrusion, one needs both real-time observation tools (Ogilvy et al., 2009), e.g. to position the seawater freshwater interface, and reliable predictive models, if additional natural (sea level variations, recharge) or man-made (groundwater pumping) factors are modified. The first task requires robust measuring technologies, whereas the second one depends mainly on numerical modelling and its calibration. Our global objective in this context is to show with other authors (Compte and Banton, 2007; Goldman and Kafri, 2006; Kirsch, 2006; Wilson et al., 2006) that both tasks may benefit from non-invasive to minimally intrusive geophysical measurements, under certain conditions.

On a worldwide scale, seawater intrusion occurrences are generally identified by observing anomalous chloride concentrations in coastal aquifers, using chemical or electrical well measurements (Bear et al., 1999). Depending on the concentration of Cl- ions (Kirsch, 2006), water can be classified as fresh $(<150 \mathrm{mg} / \mathrm{l}$, $<500 \mu \mathrm{S} / \mathrm{cm})$, brackish $(150-10,000 \mathrm{mg} / \mathrm{l}, 500-25,000 \mu \mathrm{S} / \mathrm{cm})$, or brine $(>10,000 \mathrm{mg} / \mathrm{l},>25,000 \mu \mathrm{S} / \mathrm{cm})$. Since the bulk electrical resistivity/conductivity is closely connected to the pore water salinity, brackish or brine water is generally a good target for electrical or electromagnetic exploration. Numerous examples of case studies may be found, for example in Bear et al. (1999); Goldman and Kafri (2006); Kirsch (2006). 
Direct-current (DC) electrical methods are generally used to explore the subsurface down to approximatively $100 \mathrm{~m}$, whereas time-domain electromagnetic soundings (TDEM) may reach depths of several hundreds of meters. DC resistance data are often processed using 2D inversion algorithms, yielding a cross-sectional image, or tomogram (electrical resistance tomography or ERT), of the area in terms of bulk electrical resistivity (Yang et al., 1999). Such sections may also be created using several adjacent vertical electrical soundings (VES) but these reconstructed 2D sections may suffer from inversion artefacts due to the inadequate 1D modelling of the subsurface, if lateral variations are present. In the examples provided by Kirsch (2006), an assessment of freshwater reservoirs is demonstrated through VES models (Ketelsen and Kirsch, 2004) identifying a freshwater aquifer as a 130-180 Ohm-m layer, dipping inland at shallow depths. According to the authors, this indicated that the seawater intrusion was shallower than expected from the Ghyben-Herzberg approximation. VES limitations in the presence of significant lateral variations have led engineers and scientists to use 2D imaging approaches (tomography), which may take into account the spatial variability in the direction of the profile. In a recent contribution, Wilson et al. (2006) used VES soundings to grossly delineate the spatial extent of a seawater intrusion and 2D electrical tomography to image the interface in more detail. These authors compared inverted bulk resistivity values with water conductivity and Clconcentrations to retrieve the Archie's formation factor and a relationship between water quality and earth resistivity. Assuming that no clays were present, they used bulk resistivity isolines to map the interface and compared them visually with $1 \%$ mixing isolines from hydrogeological models. This was in turn used to understand the structure and evolution of the saline interface. Other "non-electrically sensitive" methods, such as seismic reflection (Foyle et al., 2002; Shtivelman and Goldman, 2000), may also be used to assist the building of a hydrogeological conceptual model by providing structural information (stratigraphy, tectonics). For example, combined interpretation of electrical resistivity, reflection seismic and gravity data may allow one to elucidate the relationship between phreatic and confined aquifers, to obtain detailed stratigraphic information of the main aquifer, and to provide a quantitative geological section that could be used for aquifer modelling (Balia et al., 2003). 
Hydrogeological modelling of density-dependent flow and transport is a well-established methodology (Bear et al., 1999). Reliable numerical models are now able to represent a wide variety of physicochemical phenomena occurring in seawater intrusion such as chemical precipitation, heat flux exchanges or nutrient transportation. Paradoxically, characterizing coastal aquifers remains a major challenge and the more sophisticated models become, the more parameters are generally needed. According to Sanz and Voss (2006), the most important hydrogeological parameters to calibrate seawater intrusion models are space-dependent hydraulic conductivity and dispersivity. However, measuring these parameters in situ at the scale of seawater intrusion (which can reach several kilometres) is still a difficult task (Dagan, 2006). To support and complement hydrogeological data, geophysical techniques are increasingly used in hydrogeological model parameterization (Binley et al., 2002; Deiana et al., 2008; Looms et al., 2008; Rubin and Hubbard, 2005; Tronicke and Holliger, 2005; Vereecken et al., 2006) since they may provide spatially distributed parameters on a finer grid than conventional wells. Scarcity of hydrogeological data at the seawater intrusion scale may account for the limited number of hydrogeophysical parameter estimation studies in seawater intrusion problems (Antonsson et al., 2006; Compte and Banton, 2007; Koukadaki et al., 2007; Lebbe, 1999; Wilson et al., 2006). As an example, Koukadaki et al. (2007) modelled a simplified saltwater-freshwater interface using the Ghyben-Herzberg relationship where the calibration is performed on hydraulic heads. For this purpose, they used ERT-derived hydraulic conductivities computed using Archie's law but failed to address inherent geophysical inversion and petrophysical limitations. Another recent study is provided in Compte and Banton (2007), where the authors propose a so-called cross-validation methodology. They visually compare on one hand, ERT with chloride concentrations obtained from hydrogeological modelling, and on the other hand apparent resistivity data sets with synthetic ones generated by linking simulated salt concentrations with bulk resistivity via a site-specific Archie's law. According to the authors, this approach leads to an increased confidence of hydrogeological models. However, they do not address inherent geophysical inversion and petrophysical limitations either, which are critical factors in the success of hydrogeophysical parameter estimation (Day-Lewis et al., 2005; Kemna et al., 2006; Linde et al., 2006). 
As seen above, objectives of seawater intrusion geophysical studies may either be detection, imaging, or model building. For such studies, success relies on the interpretation of spatially and temporally dependent values (in this case bulk electrical resistivity) to some diagnostic values (generally salt concentration percentage or water electrical conductivity). It implies that the computed geophysical values are representative of the true ones, and that a petrophysical law applies adequately for all points. In other words, this assumes that the geophysical image is equally well resolved, and that the petrophysical relationship is stationary in space. To address resolution issues, geophysicists may use image appraisal tools as stressed by Alumbaugh and Newman (2000); Day-Lewis et al. (2005); Friedel (2003). For example, Alumbaugh and Newman (2000) have analyzed the use of various linearized functions for the a-posteriori appraisal of $2 \mathrm{D}$ and $3 \mathrm{D}$ nonlinear electromagnetic inversion (applicable to 2D ERT). According to the authors, the linear results spatially appear quite reasonable and the linearized approximations are yielding valuable information about the accuracy and resolution provided by the image and the non-uniqueness of the inversion problem. This should be taken into account, in particular when attempting hydrogeophysical parameter estimation, to filter part of the geophysical image (for example by computing empirically a threshold (Nguyen et al., 2007)) or to weight their reliability using the diagonal terms of the model covariance matrix. Petrophysical uncertainties on the other hand are more difficult to compute because of the necessity to estimate a site-specific relationship and the limited knowledge of the validity of this relationship away from the calibration points. However, the assumption of a stationary petrophysical law is often the only possibility and several successful case studies are given in the literature (Hubbard et al., 2001; Kemna et al., 2002; Purvance and R. Andricevic, 2000).

The objective of this work is to assess the use of smoothness-constrained 2D electrical tomographic images for marine seawater intrusion detection, and to constrain hydrogeological parameters. We will use different hydrogeological simulations, considering first a homogeneous model with several transverse dispersivity values, then a heterogeneous, layered model. These models are scaled to reflect the overall geometrical setup of a field site, located in Almeria, Spain. We will further demonstrate ERT potential under field conditions 
using surface, in-hole, and surface-to-hole resistance data, for which ground-truth calibration data is available in deep boreholes.

Following this introduction, we briefly outline the electrical imaging approach used in this study, and recall associated tools for image appraisal. We will then present the seawater intrusion simulations results and their conversion to geophysical earth resistivity models. The results of these transformations are then discussed and analyzed before presenting the field data and their interpretation. Finally, we present our conclusions and perspectives following this work.

\section{Electrical imaging}

Significant advances in the resistivity method in the 1990's (see Binley and Kemna (2005) for an overview) resulted in an increasing number of engineering and environmental applications. A drawback from this increasing interest is that some users non-familiar with inversion theory may use commercially available softwares as a black box and fall in interpretation pitfalls. Below, we briefly outline the imaging procedure applied in this study and recall approaches for image appraisal.

2.1. Forward model and inversion. We here assume that the bulk electrical conductivity distribution $\sigma_{b}\left[\frac{S}{m}\right]$ is constant in the direction perpendicular to the image plane, in agreement with typical seawater intrusion geometries along linear shores. The corresponding 2.5D electrical forward problem is then solved, for the electric potential as a response to a point-source current excitation, for given boundary conditions by means of the finite-element (FE) method. See Kemna (2000) for details of the forward model implementation employed in this study.

We used a standard smoothness-constrained inversion algorithm (e.g. LaBrecque et al. (1996); Loke and Barker (1996)) to invert a set of log-transformed resistance data, $d_{i}=\ln \left(r_{i}\right), r_{i}\left[\frac{V}{A}\right]$, into a $2 \mathrm{D} \log$ transformed bulk electrical conductivity distribution, parameterized into pixels $m_{j}=\ln \left(\sigma_{b j}\right)$. Here, the objective function

$$
\Psi(m)=\Psi_{d}+\lambda \Psi_{m}
$$




$$
\Psi_{d}=\left\|W_{d}(d-f(m))\right\|^{2}
$$

and $\Psi_{m}$ is the measure of first-order model roughness,

$$
\Psi_{m}=\left\|W_{m} m\right\|^{2}
$$

with $W_{d}$ denoting data weighting matrix, $f()$ forward operator, and $W_{m}$ model roughness matrix. We assume uncorrelated data errors so that $W_{d}$ is a diagonal matrix; its entries $w_{i}$ represent the inverse relative resistance errors. Due to the nonlinearity of the problem, the minimisation of $\Psi(m)$ results in an iterative Gauss-Newton scheme where, at each iteration $q$, the Jacobian matrix $J_{q}$ (sensitivity) is computed . We refer to Kemna (2000) for more details on the implementation of the iterative scheme (choice of $\lambda$, step-length damping etc.). We start the inversion with a homogeneous model, determined from the mean measured response. The iteration process is stopped when the RMS (root-mean-square)value of error-weighted data misfit $\epsilon^{R M S}$ reaches the value 1 for a maximum possible value of $\lambda$. The latter aspect is important to actually fulfil the optimization criterion (smoothest model, subject to fitting the data). Moreover it is important, in order to avoid imaging artefacts, to not minimize the data misfit below the desired target value. For the field data sets, we estimated the average resistance error from deviations between normal and reciprocal measurements following the approach of Koestel et al. (2008); Slater et al. (2000)).

2.2. Image appraisal. When interpreting resistivity imaging results, one must be aware of the spatial variation of the resolution throughout the image plane. Several approaches may be used for the computation of an appraisal quantity (see Binley and Kemna (2005)) but they are rarely used in practice (Compte and Banton, 2007; Wilson et al., 2006).

Classic inversion theory (Parker, 1994) defines the explicit computation of the resolution matrix for a non-linear problem:

$$
R=\left(J^{T} W_{d}^{T} W_{d} J+\lambda W_{m}^{T} W_{m}\right)^{-1} J^{T} W_{d}^{T} W_{d} J
$$


The matrix $R$ is often represented using its diagonal or by defining a resolution radius using off-diagonal terms (Alumbaugh and Newman, 2000; Day-Lewis et al., 2005; Ramirez et al., 1995). Ideally, $R$ should be close to the identity matrix to achieve perfect resolution. However, as stressed by Meju (1994), a perfect resolution does not imply that the obtained model is accurate or reliable. One of the major drawbacks of this approach is the relatively high computation cost.

We use an alternative, faster approach in this study based on the data error-weighted cumulative sensitivity (Kemna, 2000):

$$
s=\operatorname{diag}\left(J^{T} W_{d}^{T} W_{d} J\right)
$$

This cumulative sensitivity distribution shows how the data set is actually influenced by the different model cells, or in other words, how specific areas of the imaging region are "covered" by the data, by analogy to ray-based tomography. It must be emphasized, however, that a high sensitivity region may not necessarily be well resolved, but rather represents a favoring factor (Kemna, 2000).

\section{SALine intrusion models}

3.1. Density-dependent flow and transport. The simulation of seawater intrusion into the coastal aquifer was performed using the finite-difference model HST3D (Heat and Solute Transport in 3 Dimensions) by Kipp (1987). The three governing equations of heat, solute and fluid mass are coupled through the interstitial pore velocity, the dependence of the fluid density on pressure, temperature, and solute-mass fraction, and the dependence of the fluid viscosity on temperature and solute-mass fraction. Heat is not considered in this study. The flow equation used in the model is based on the fluid mass-balance equation and can be written as

$$
\frac{\partial \epsilon \rho}{\partial t}=\nabla \cdot \rho \frac{k}{\mu}{ }_{8}(\nabla p+\rho g)+q \rho^{*}
$$


where $p$ is the fluid pressure $[\mathbf{P a}], t$ is the time $[t], \epsilon$ is the effective porosity [dimensionless], $\rho$ is the fluid density $\left[M / L^{3}\right], \rho^{*}$ is the density of a fluid source $\left[M / L^{3}\right], k$ is the porous-medium intrinsic permeability tensor $\left[L^{2}\right], \mu$ is the fluid viscosity $[M / L t], q$ is the fluid source flow-rate intensity $\left[t^{-1}\right]$ and $z$ is elevation above a reference point $[L]$.

After solving the flow equation, the interstitial pore velocity is obtained from Darcy's law as

$$
v=-\frac{k}{\epsilon \mu}(\nabla p-\rho g \nabla z)
$$

where $v$ is the interstitial-velocity vector $\left[L t^{-1}\right]$. In a similar manner, the solute-balance equation used in the model is:

$$
\frac{\partial(\epsilon \rho \omega)}{\partial t}=\nabla \cdot \epsilon \rho D_{s} \nabla \omega+\nabla \cdot \epsilon \rho D_{m} I_{w} \nabla \omega-\nabla \cdot \epsilon \rho v \omega+q \rho^{*} \omega^{*}
$$

where, $\omega$ is the mass fraction of solute in the fluid phase [dimensionless], $\omega^{*}$ is the mass fraction of solute in the fluid source [dimensionless], $D_{s}$ is the mechanical dispersion tensor $\left[L^{2} t^{-1}\right]$ and $D_{m}$ is the effective molecular diffusion of the solute $\left[L^{2} t^{-1}\right]$. In HST3D the fluid density is a function of pressure, solute concentration, and temperature (excluded here). It is incorporated into the code as

$$
\rho(p, T, \omega)=\rho_{0}+\rho_{0} \beta_{p}\left(p-p_{0}\right)+\rho_{0} \beta_{\omega}\left(\omega-\omega_{0}\right)
$$

where $\rho_{0}$ is the fluid density at a reference pressure, $p_{0}\left[M / L^{2} t\right]$, temperature, $T_{0}[T]$, and mass fraction, $\omega_{0}$ [dimensionless], $\beta_{p}$ is the fluid compressibility $\left[L^{2} t / M\right]$ and $\beta_{\omega}$ is the slope of the fluid density as a function of mass fraction divided by the reference fluid density [dimensionless].

\subsection{Discretization and boundary conditions. A centred-in-space and fully implicit-in-time finite-difference} scheme was chosen as a compromise between stability and accuracy. This scheme eliminates numerical dispersion caused by spatial differentiation, but not by temporal differentiation. A fully-implicit scheme adds numerical dispersion approximately proportional to the time step length. An inappropriate choice of time 
step could therefore add more numerical dispersion than physical dispersion, but no significant numerical dispersion was observed with a time step size of less than 20 days. When choosing the grid discretization, two contradictory criteria are required to be fulfilled, stability and manageable simulation times. To minimize the risk of instability when using central-in-space approximation the grid-Peclet criterion should be fulfilled (Daus et al., 1985):

$$
p_{e}=\frac{v \Delta x}{D} \leq 2
$$

where $\Delta x$ nodal spacing $[L]$, and $D$ is dispersion $\left[L^{2} / T\right]$. The criterion determines the relative size of advection and dispersion on model element basis and basically states that smaller hydrodynamic dispersion requires smaller discretization (assuming the velocity does not change). However, the criterion can only be regarded as a guideline since acceptable solutions have been obtained with Peclet numbers as high as 10 (Huyakorn and Pinder, 1983; Sudicky, 1989). Therefore a grid spacing determined solely on the basis of the Peclet number may be conservative, (i.e. the grid may contain too many nodes) and result in impractically long simulation times. A horizontal grid spacing of 10 meters and vertical spacing of 1 metre proved adequate for the current intrusion model setup.

A 2D vertical cross-sectional model was established to simulate saltwater intrusion of dimension similar to that encountered in our field experiment. As illustrated in figure 2, the model domain is rectangular with a length of $3000 \mathrm{~m}$ and a depth of $90 \mathrm{~m}$. The flow system is defined by two fixed pressure (Dirichlet) boundaries. A hydrostatic pressure distribution equivalent to $0 \mathrm{~m}$ and $2.5 \mathrm{~m}$ was applied at the sea- and upstream boundary, respectively. The bottom boundary is no flow and the top is a free-surface (water table) boundary condition. For the solute transport, associated concentrations as scaled mass fractions are used for both the sea- and upstream boundary, with values of 1 and 0 , respectively. The system parameters reflect site conditions at Almeria and are outlined in table 1.

In order to obtain steady state conditions the simulation ran for 50000 days. With an initial condition of freshwater in the whole domain, the saltwater starts intruding from the sea boundary in the form of a wedge 
in the lower part of the aquifer. When saltwater meets the freshwater from the upstream boundary, the two fluids mix and a transition (mixture) zone forms between them. The shape of the intruding wedge and the thickness of the transition zone is governed by the hydraulic conductivity and the dispersivity values and is influenced by the boundary conditions, in particular on the freshwater side. The mixture of the two fluids, which is lighter than the saltwater, rises and is transported towards and out of the sea boundary by the freshwater gradient. The result is an establishment of a saltwater convection cell within the aquifer, where a dynamic equilibrium is ultimately obtained when the amount of salt entering through the lower portion of the sea boundary equals the salt leaving through the upper part of the sea boundary.

3.3. ERT simulation of saline intrusion synthetic model. In order to produce electrical tomography images, we converted the water salinity distributions, expressed as scaled mass fractions, obtained from the density dependent flow and transport simulations to bulk electrical resistivity. To achieve this, we first converted the mass fraction distribution $\omega$ to water electrical conductivities $\sigma_{w}$ by means of the following relationship involving electrical conductivities $\sigma_{w f}$ and $\sigma_{w s}$ of fresh and sea water, respectively:

$$
\sigma_{w}=\left[(1-\omega) \cdot \sigma_{w f}+\omega \cdot \sigma_{w s}\right]
$$

In this study, we used $\sigma_{w f}=2,000 \mu S / \mathrm{cm}$ and $\sigma_{w s}=50,000 \mu \mathrm{S} / \mathrm{cm}$, which correspond to measured conductivities on well samples. Then, we used Archie's law and a one layer (aquifer) over a half-space (aquitard) geological model (matching the hydrogeological one, figure 2) in order to delimit the areas where two different petrophysical models apply (see text below and figure 3). Archie's law (1942) relates empirically bulk electrical conductivity $\sigma_{b}$ and the conductivity of the pore solution $\sigma_{w}$ :

$$
\sigma_{b}=\frac{\Phi^{m}}{a} \sigma_{w} S_{w}^{n}
$$

In Archie's law, the observed proportionality between the two electrical conductivities is found to be dependent on the porosity $\Phi$ and the water saturation $S_{w}$ (1 if fully saturated). In equation (3.7), $m$ and $n$ are usually referred to as the cementation exponent and the saturation exponent, respectively, and $a$ is a proportionality constant. The quantity $F=\frac{a}{\Phi^{m}}$ represents the so-called formation factor. These parameters 
are mainly controlled by the pore space geometry (constrictivity, tortuosity).

Archie's law validity depends on the contribution of electrical surface conduction to the bulk electrical conductivity. When surface conduction may not be neglected (e.g. in the presence of clays), one must modify Archie's law in order to account for this effect (e.g., Waxman and Smits (1968)):

$$
\sigma_{b}=\frac{\sigma_{w}}{F}+\sigma_{\text {surf }}\left(\sigma_{w}\right)
$$

In equation (3.8), the surface conduction term $\sigma_{\text {surf }}\left(\sigma_{w}\right)$ may also depend on water electrical conductivity (e.g., Revil and P.W.J. (1998)). Since, in practice, this dependence is difficult to separate from the first term on the right-hand side of equation (3.8), one may also write equation (3.8) as

$$
\sigma_{b}=\frac{\sigma_{w}}{F^{\prime}}+b
$$

where $F^{\prime}$ corresponds to an effective formation factor, which includes both the dependence of pore-water related bulk electrical conductivity and of surface electrical conduction on water conductivity, and $b$ corresponds to a surface conduction contribution independent of the water conductivity.

For our study, we chose to use site-specific petrophysical relationships, in order to relate simulations with field results. Figure 3 shows a plot of the bulk electrical conductivity versus water salinity for different samples from the aquifer and of impermeable Pliocene bedrock of the Andarax river site. These were measured in the laboratory at various salinities on disturbed samples and may therefore be only partly representative of field conditions. The formation factors of the aquifer and aquitard materials were determined by fitting equation (3.9) to the data points shown in figure 3. One can see that in the relevant salinity range, the bulk electrical conductivity variations of the sediments are controlled by water salinity changes, which implies that the surface conduction term $b$ may be neglected. Therefore, one can directly relate bulk electrical conductivity variations to salinity concentration variations. One can also see that the aquitard materials exhibit higher bulk electrical conductivity values than the aquifer materials for the same water electrical 
conductivity. However, since the two petrophysical relationships overlap over a wide range of electrical conductivities, it is generally not possible to discriminate between the two lithologies from bulk electrical conductivity. However, if time-lapse data are available, one could distinguish the two formations by (1) observing that bulk electrical conductivity related to aquifer materials exhibits larger variations than aquitard materials, due to the latter's low hydraulic conductivity, and (2) by considering independent water salinity measurements.

Once the water salinity distribution were modelled, we converted the results to an electrical resistivity distribution (figure 4) on the ERT forward grid (cell size in the domain of interest: $10 \mathrm{~m}$ horizontal and $1.25 \mathrm{~m}$ vertical) using equations (3.6) and (3.9) (neglecting the surface conduction term $b$ ) and a standard interpolation function. From there, we used the electrical finite-element forward code to simulate any type of desired electrical measurement. The electrode layout (figure 4) was chosen in order to fit a future permanent installation at the field site. It consists of a $1 \mathrm{~km}$ surface line and two approximately $90 \mathrm{~m}$ deep boreholes. The surface line is equipped with electrodes every $10 \mathrm{~m}$ whereas the borehole electrodes have a $5 \mathrm{~m}$ vertical spacing, allowing better resolution at depth. The chosen measurement protocol is a standard "skip-1" dipoledipole. Simulated resistances exhibiting very low values $(<5 e-4 \Omega)$, corresponding to very large geometric factors, were disregarded in order to simulate a minimum voltage that can be reliably determined by typical ERT instruments, e.g., $0.5 \mathrm{mV}$ for a current of $1 \mathrm{~A}$ (Vanderborght et al., 2005). For this study, 7\% Gaussian noise was added to the resistance data. This level is slightly higher than the observed noise level in the field data $(5 \%)$ as to simulate a realistic worse case scenario. The inversion grid was defined using coarser vertical meshing. This is often the case when coupling geophysical and hydrogeological models since the latter generally demand a finer discretization.

3.4. Results. In a first step, we will study the imaging ability of the electrical setup defined above, to reconstruct the spatial electrical conductivity variations associated with simulated salinity distributions. The different mass fraction distributions correspond to different steady state scenarios for a given set of boundary 
and initial hydrological conditions and predefined hydrogeological parameters (see section 3.1).

Let us first examine the overall procedure illustrated in figure 4. At first glance, the resistivity distribution seems pretty well resolved (compare figures $4 \mathrm{c}$ and d), except for the region deeper than $100 \mathrm{~m}$, where no intrusion occurs. To detect or to position the interface, which is a primary objective of ERT in this context, one must relate bulk electrical resistivity values to either water electrical resistivity (or its inverse, conductivity), or mass fraction, diagnostic of seawater contamination. We again performed this step on the basis of equation (3.9) using the same parameters as for the "forward step" and obtained the result shown in figure 4b. Comparing now figures $4 \mathrm{a}$ and $\mathrm{b}$, the ERT-derived mass fraction image appears less correlated to the true one than the resistivity images are. If we examine carefully the mass fraction distribution up to 0.2 , we can see that there is a good agreement between the recovered image (figure $4 \mathrm{~b}$ ) and the original one (figure 4 a), despite the introduction of a $7 \%$ Gaussian noise in the electrical data. Below this level, a distortion of the interface clearly appears, in particular around $700 \mathrm{~m}$ in the $\mathrm{x}$ direction, where sensitivity (resolution) reaches a critical point as explained hereafter.

In figure 5, one can see that the cumulative sensitivity distribution of the resistivity model is asymmetric, and reflects the overall ERT configuration. Let us now examine more carefully the relation between the sensitivity distribution along two vertical lines, one located adjacent to a borehole and the other located between the two boreholes, and the correctness of the ERT-derived mass fractions (figure 5). At the bottom of figure 5, two graphs are shown in which the recovered mass fractions is plotted against the true mass fraction for the two vertical boxes shown in the sensitivity image (note that here, sensitivity, electrical conductivity, and depth are all positively correlated due to the general shape of seawater intrusion). For the line where sensitivity is constantly high, the correlation is excellent. For the second graph, this agreement gradually breaks down (reflecting the gradual variation in the sensitivity distribution) for mass fractions above 0.4. This deviation, sometimes miscalled "petrophysical breakdown", is a matter of resolution as suggested by earlier authors (Day-Lewis et al., 2005). The discrepancy between the recovered and true mass fractions originates from the incorrect inverted resistivity values; the petrophysical relationship, on the other hand 
still holds (if still valid - like in this example). We must stress that the problem of determining this fit is of crucial importance for using ERT to characterize seawater intrusion in terms of presence, position, and shape, but is not often taken into account (Compte and Banton, 2007; Wilson et al., 2006). It can only be addressed through numerical modelling or via calibration if ground-truth data is available.

As a second task, we will investigate the ability of ERT to differentiate between different seawater intrusion shapes corresponding to hydrological models run using different transverse dispersivity values $\alpha_{T}$. From a geometrical point of view, the seawater-freshwater transition zone ranges from diffuse to sharp, corresponding to $\alpha_{T}$ values ranging from $2.5 \mathrm{~m}$ to $0.5 \mathrm{~m}$, respectively. This range of values is in agreement with values adopted in the literature (Oude Essink, 2003; Panday et al., 1993; Reily and Goodman, 1987; Voss and Souza, 1987). Transverse dispersion is important, since it generates a transition zone, responsible for seawater circulation and for salinity of pumped water (Dagan, 2006). The results of these simulations and electrical imaging are summarized in figure 6 where two sets of mass fraction isolines (true and ERT-recovered) are shown. In general, the ERT-recovered mass fraction isolines correspond relatively well with the true ones for the different scenarios, except for the area around 700m mark in the $\mathrm{x}$ direction, and for the sides where no electrodes are located. In addition, figure 6 indicates that the chosen electrode configuration only allows mass fractions up to 0.2 to be recovered correctly in all different scenarios involved. If the transition zone is entirely located in well resolved areas, as assessed e.g. by cumulative sensitivity distribution, it is possible to correctly determine the width of the transition. In our case, ERT yields less reliable results for diffuse interface simulations since the end of the transition is then located in deeper areas. Paradoxically, although we are using a smoothness constraint to regularize the ERT inverse problem, in our simulations the recovery of the transition zone is better the sharper it is.

A critical task for ERT, for which it is often "promoted", is the recovery of heterogeneity. We illustrate this point by attempting to detect the presence of a low permeability layer or, more accurately, its lateral continuity (since its presence would be already given by borehole information) for two scenarios where the electrical conductivity $\sigma_{w f}$ varies (equation (3.6)). The formation factor (equation (3.9)) is taken as uniform for the recovery over the entire image plane (but depends on the lithology for the simulation), assuming that 
we have limited knowledge of the spatial stationarity of the petrophysical relationship. This could illustrate two regional settings, one for which the freshwater is relatively free of chlorine ions and one where the "fresh" water is more brackish (as for the region of Almeria). Figure 7 shows an exemplary mass fraction isoline (0.01) for these scenarios in conjunction with the corresponding cumulative sensitivity distribution, clipped for values smaller than $-10^{-5}$ of the maximum value. This threshold was determined empirically using the breakdown limit observed in figure 5 (bottom right). The difference between the two sensitivity distributions in figure 7 arises from the two different fresh water values used in the petrophysical relationships. From the top figure, we see that the true isoline is located far in the clipped (low) sensitivity region and that the recovered mass fraction isoline is far from the true one. For the other scenario (bottom figure), the ERT recovered isoline is closer to the true one and could indicate the continuity of the low permeability layer. The latter isoline is, in comparison with the top figure, located nearer to the edge of the clipped sensitivity region, indicating a better resolution. This clearly further supports the necessity to use an image appraisal tool in order to validate the derived information (heterogeneity) from ERT images.

\section{The Site of Almeria}

4.1. Presentation of the site. Situated in the Southeast of Spain (figure 8), the area coincides with a valley in the lower part of the river Andarax, which in this stretch supports a water flow only during flood conditions. Precipitation in the area is low, with mean values in the order of $300 \mathrm{~mm} /$ year, concentrated over short periods (Pulido-Bosch et al., 2004). The Mediterranean coastal region of southern Spain has undergone a startling economic development over the last 20 years. This is due not only to the long-established tourist industry but also to changes in the pattern of agriculture in which traditional farming has given way to greenhouse cultivation. Because of the high profitability of this method of agriculture, the surface area under cultivation has increased notably and so has the water demand. The main source of water in the area is from groundwater and in many cases the withdrawal has led to aquifer overexploitation and seawater intrusion (Benavente, 1985). The economy of the region depends to a large extent on the availability of water of adequate quality for crop irrigation, so that marine intrusion and salinization could endanger the 
economic future of the coastal areas (Pulido-Leboeuf, 2004; Van Cauwenbergh et al., 2006).

The Lower Andarax valley is enclosed by the Sierra Alhamilla, with its mainly metapelitic outcrops and by the Sierra de Gador, which constitutes a limestone/dolomite massif. The area is infilled by Miocene and Pliocene detritic deposits of quite diverse lithology (marls, sandy silts, sands and conglomerates) and numerous gypsiferous evaporite intercalations. The micashists and quartzites are practically impervious and the carbonate formation is highly porous, with permeability due to fissuring and/or karstification. The postorogenic materials show a highly variable permeability. The Miocene and Pliocene marly formations have very low permeability, whereas the Pliocene deltaic deposits, the Quaternary and Plioquaternary formations are water-bearing. The hydrogeological units are defined in terms of three units, the detrital, the carbonate and the deep aquifers (Pulido-Bosch et al., 1992). The Detrital Aquifer runs the entire length of the valley. It includes Quaternary materials, both alluvial and deltaic, together with Pliocene, deltaic, sandy-silt conglomerates. The thickness of the aquifer varies from $200 \mathrm{~m}$ in the Pliocene materials in the area of Santa Fe, to $40-80 \mathrm{~m}$ in the Quaternary deltaic materials. Consistent with the piezometric evolution, the aquifer shows sharp fluctuations in level, with a clear seasonal recovery. In low-lying areas, the area registering piezometric head drop has increased over the last few years and even hydraulic head cones below the sea level have appeared in the areas of greatest exploitation. The Carbonate Aquifer of the Sierra de Gador consists of Alpujarride limestones and dolomites, with local Miocene calcarenites that extend along the entire edge of the sierra. The Deep Aquifer, situated in the centre of the valley is confined and is compartmentalized into blocks. It is composed of limestone dolomite strata with some layers of quartzite that form the basement of the depression.

4.2. Electrical measurement setup. The electrical profile was deployed in the bed of the River Andarax (figure 8) in the lower part of the delta, where it is invariably dry for most of the year except for a few flash floods in the autumn-winter months. The measurement campaign was performed for one part using a temporary electrode surface layout with $20 \mathrm{~m}$ spacing of $2.3 \mathrm{~km}$ long with a Supersting system and for another part, using a research prototype system (Ogilvy et al., 2009) and a permanent electrode array. The 
latter was buried in a trench about $1 \mathrm{~m}$ deep and $1.6 \mathrm{~km}$ in length, extending upstream from a point about $300 \mathrm{~m}$ from the shoreline. The subsurface array has electrode take-outs at $10 \mathrm{~m}$ intervals. The measurement system used was developed under the EU ALERT project (Ogilvy et al., 2007) and has 288 electrodes, all of which are addressable so that any electrode array may be selected. For control purposes, 3 deep boreholes (B320, B820, and B1320, shown in figure 8) were drilled through the Quaternary aquifer sediments into the relatively impermeable Pliocene marls at a depth of $100 \mathrm{~m}$. These boreholes were spaced about 500m apart on the electrical line to provide ground-truth and to assist image calibration. Electrode arrays with take-outs at $1 \mathrm{~m}$ spacing were attached to the outer PVC casing of two of the boreholes to facilitate surface-to-hole measurements (figure 8) for the permanent array.

Data have been collected using both surface (dipole-dipole and Wenner) and borehole electrode configurations. Data quality has been checked using standard protocols (stack and reciprocals) and proved to be satisfactory (figure 9) for both surface and surface-to-borehole configurations. Water electrical conductivity measurements were also conducted in the deep borehole along with bulk electrical resistivity measurements (in-hole measurements using borehole electrodes).

4.3. Results. We will now examine the potential of electrical imaging in seawater intrusion studies under field conditions. Figure 10 shows the result of the inversion of a dipole-dipole surface dataset (with a maximum inter-dipole spacing-number of 6 ) gathered along the $2 \mathrm{~km}$ line. Based on an error analysis of the datasets (figure 9), a resistance noise level of $6 \%$ was assumed for the inversion. However, tests have shown that decreasing or increasing the noise level by a few per cent does not affect the inversion result in qualitative terms. From figure 10a, we clearly see a low resistivity body forming a wedge in the subsurface from the shoreline to 1.5 to $2 \mathrm{~km}$ inland. The shape of this feature clearly reflects a seawater intrusion, similar to the Ghyben-Herzberg approximation. In order to convert the electrical image into mass fraction, we applied the petrophysical relationships given in equations (3.6) and (3.9), using the experimentally determined parameters $\sigma_{w s}, \sigma_{w f}$ and $F$. The result of the conversion is shown in figure $10 \mathrm{~b}$. Assuming that seawater intrusion is defined by a mass fraction of chlorine higher than 0.1 , we can see that we can identify an intrusion toe at approximately $1.5 \mathrm{~km}$ inland. Figure $10 \mathrm{~b}$ also reveals that a mass fraction of 1 , corresponding to pure 
seawater, is not retrieved. This must be attributed to a lack of resolution and/or inaccurate petrophysical parameters. We also note the good correlation in figure 10b between the image mass fraction lines and the water electrical conductivity logs in the boreholes.

To assess further the quality of the ERT result, we compared it with geological, water electrical conductivity, and bulk electrical resistivity logs in two boreholes at 320 and $820 \mathrm{~m}$ along the ERT section (figure 11. We plotted the vertical profiles of the resistivity distributions inverted from the surface data and from the in-hole data at the positions of the boreholes. These ERT "logs" show a good correlation. Moreover, they correlate well with the respective water electrical conductivity log, indicating that ERT images are mainly sensitive to the amount of dissolved salt rather than to lithology. This suggests that the width of the transition zone may be estimated at this site to a reasonable degree using surface ERT. However, figure 11 also shows that the surface ERT only resolves the larger-scale variation but fails to capture the meterscale variations (most likely related to lithological variations). Consequently, surface ERT may only be able to constrain upscaled hydrological parameters or features. By comparing the formation factors computed in-situ (using the water and bulk electrical resistivities from boreholes measurements; figure 11) and from samples in the laboratory (figure 3), we can see that there is a relatively large discrepancy between the two, which may explain the fact that the mass fraction does not reach a maximum value of 1 where seawater is located (see above).

The permanent electrode array allowed us to test surface-to-borehole ERT; however, cross-hole ERT surveys were not possible, due to the large distance between the boreholes relative to their depth. Figure 12 shows the image inverted from the surface-to-borehole (dipole-dipole) data (assumed resistance noise level of $4 \%$; see figure 9). There is a general agreement between the surface and surface-to-borehole images; however, the interpretation in terms of the shape of the intrusion front is not obvious for the surface-to-borehole image. This may be attributed to the laterally much more heterogeneous sensitivity (resolution) pattern of a surface-to-borehole survey compared to a surface survey (Tsourlos et al., 2004), making interpretations of 
surface-to-borehole images more difficult. In addition, the lateral coverage of the surface-to-borehole ERT survey is relatively weak given the overall extent of the seawater intrusion.

\section{Conclusions And Perspectives}

In this work, we evaluated the potential of smoothness-constrained 2D electrical imaging to characterize seawater intrusion. We used both synthetic data from hydrological simulations of seawater intrusion, field data, and deep boreholes logs (geology, bulk resistivity, water electrical conductivity). The setup that we adopted in the numerical study is representative of the Almeria field site; however our results and conclusions may be extrapolated to coastal aquifer studies in general, if clays play a negligible part in the conduction of electric current due to high salinity content. The latter should often be the case in arid to semi-arid coastal aquifers where groundwater resources are vital to the population.

Our simulation results indicate that the subsurface resistivity distribution associated with saline intrusion can be reasonably well recovered by ERT. However, mass fraction could only be accurately recovered up to values of 0.2 . The higher mass fractions at larger depths are only poorly resolved. The low cumulative sensitivity values in these regions clearly indicate that the loss of resolution with depth (away from the electrodes) accounts for the mismatch between recovered and true mass fractions. Nevertheless, if the transition zone is entirely located in fairly sensitive (resolved) areas, it is possible to capture its extent. Paradoxically, although we used a smoothness-constrained inversion scheme we were better able to recover sharper (but still smooth) transition zones since these were located closer to the electrodes.

A clear recommendation that emerges from this study is that if one uses ERT images to constrain a hydrogeological model (to calibrate dispersivity, to position the interface, to detect heterogeneity, or to determine the width of the transition zone), one must not make use of the entire image plane but only consider, on the basis of image appraisal tools, reliable regions. We here employed an empirical approach to determine at which sensitivity value the correlation between the targeted mass fraction and the ERT-recovered one breaks down, based on synthetic modelling. We then used this value as a threshold to restrain the interpretation of the ERT image at a certain location. This is one approach and other alternatives exist, such as the use of 
the resolution matrix or the comparison with ground truth data (if available).

We tested ERT at the site of Almeria and assessed its potential using ground truth information. ERT detected the presence of seawater intrusion and delineated its shape, forming a wedge whose toe reaches approximately $1.5 \mathrm{~km}$ inland. This is confirmed by borehole data. Interestingly, we were not able to recover a mass fraction of 1 , although boreholes indicated pure seawater. Comparison between in-situ and laboratory formation factors indicates a discrepancy which could partly explain this. We believe that this is not an issue of limited depth resolution of surface ERT, since the extracted surface ERT and in-hole ERT (not suffering from a loss of resolution with depth) bulk resistivity logs show an excellent agreement in terms of the overall behaviour as dominated by chloride concentration. Moreover, the ERT "logs" also correlate well with the water electrical conductivity logs, indicating that ERT images are mainly sensitive to the amount of dissolved salt (large-scale variations) rather than to lithology (small-scale variations). The log comparison further showed that we cannot expect to resolve meter-scale variations at depth and that surface ERT may only be able to constrain upscaled hydrological parameters or features. The upscaling factor may be determined using image appraisal tools.

The surface-to-borehole imaging result suggests that the laterally heterogeneous resolution pattern of this setup may dominate the image characteristics compared to the laterally more homogeneous resolution pattern of surface ERT, complicating - in addition to only little lateral coverage - reliable interpretations in terms of the shape of the intrusion front.

We are continuing to study the use of ERT images as data for constraining the hydrological inversion of seawater intrusion model parameters. This will in particular require the inclusion of the petrophysical parameter relationships in the inversion process. 
487

We would like to thank the associate editor Lee Slater and the two reviewers, Kamini Singha and Mark Goldman for their pertinent comments and suggestions, which have greatly improved this manuscript. We also thank Frederic Day-Lewis for fruitful email exchanges. We would like also to thank all the people who contributed to this work on the field, in Almeria, and in the laboratory of the Research Center of Juelich. This work is part of the EU project ALERT (GOCE-CT-2004-505329). We thank also the Fonds de la Recherche Scientifique - FNRS (Belgium) and the University of Copenhagen for providing logistical support to this research. 


\section{REFERENCES}

D.L. Alumbaugh and G.A. Newman. 2000. Image appraisal for 2-D and 3-D electromagnetic inversion. Geophysics, 65:1455-1467.

A. Antonsson, F. Nguyen, P. Engesgaard, and A. Kemna. 2006. Constraining a 2D density-dependent saltwater intrusion model using electrical imaging data. In 1srt SWIM-SWICA - First International Joint Salt Water Intrusion Conference (19th Saltwater Intrusion Meeting/3rd Saltwater Intrusion in Coastal Aquifers), Cagliari, Chia Laguna, Italy.

R. Balia, E. Gavaudo, F. Ardau, and G. Ghiglieri. 2003. Geophysical approach to the environmental study of a coastal plain. Geophysics, 68:1446-1459.

J. Bear, A. Cheng, S. Sorek, D. Ouazar, and I. Herrera, editors. 1999. Seawater Intrusion in Coastal Aquifers - Concepts, Methods and Practices, volume 14 of Theory and Applications of Transport in Porous Media. Luwer Academic Publishers, Dordrecht/Boston/London.

J. Benavente. 1985. Las aguas subterraneas de la Costa del Solde Granada. PhD thesis, Univ. Granada-Dip. Prov. Granada.

A. Binley and A. Kemna. 2005. Hydrogeophysics, chapter DC resistivity and induced polarization methods, pages 129-156. Springer Netherlands.

A. Binley, G. Cassiani, R. Middleton, and P. Winship. 2002. Vadose zone flow model parameterisation using cross-borehole radar and resistivity imaging. Journal of Hydrology, 267:147-159.

A. H.-D. Cheng and D. Ouazar, editors. 2004. Coastal aquifer management: monitoring, modeling, and case studies. Lewis Publisher.

J.-C. Compte and O. Banton. 2007. Cross-validation of geo-electrical and hydrogeological models to evaluate seawater intrusion in coastal aquifers. Geophysical research letters, 34:L10402.

G. Dagan. 2006. Transverse mixing at fresh-water salt-water interfaces: an unresolved issue. In 1 srt $S W I M-$ SWICA - First International Joint Salt Water Intrusion Conference (19th Saltwater Intrusion Meeting/3rd Saltwater Intrusion in Coastal Aquifers), Cagliari, Chia Laguna, Italy. 
A. D. Daus, Frind E.I., and Sudicky E.A. 1985. Comparative error analysis in finite-element formulations of the advection-dispersion equation. Advances in Water Resources, 8:85-95.

F. D. Day-Lewis, K. Singha, and Binley A. 2005. Applying petrophysical models to radar travel time and electrical resistivity tomograms: Resolution-dependent limitations. J. Geophys. Res., 110:B08206.

R. Deiana, G. Cassiani, A. Villa, A. Bagliani, and V. Bruno. 2008. Calibration of a vadose zone model using water injection monitored by gpr and electrical resistance tomography. Vadose Zone J, 7:215-226.

A.M. Foyle, J.H. Vernon, and R.A. Clark. 2002. Mapping the threat of seawater intrusion in a regional coastal aquifer-aquitard system in the southeastern United States. Environmental Geology, 43:151-159.

S. Friedel. 2003. Resolution, stability and efficiency of resistivity tomography estimated from a generalized inverse approach. Geophysical Journal International, 153:305-316.

M. Goldman and U. Kafri. 2006. Hydrogeophysical applications in coastal aquifers. Applied Hydrogeophysics, pages $233-254$.

H. Guo and J.J. Jiao. 2007. Impact of coastal land reclamation on ground water level and the sea water interface. Ground Water, 45:362-367.

S.S. Hubbard, J. Chen, J. Peterson, E.L. Majer, K.H. Williams, D.J. Swift, B. Mailloux, and Y. Rubin. 2001. Hydrogeological characterization of the south oyster bacterial transport site using geophysical data. Water Resour. Res., 37:2431-2456.

P. S. Huyakorn and G.F. Pinder. 1983. Computational Methods in Subsurface Flow. Academic Press.

A. Kemna. 2000. Tomographic inversion of complex resisitivity: theory and application. PhD thesis, Bochum, Ruhr-University.

A. Kemna, J. Vanderborght, B. Kulessa, and H. Vereecken. 2002. Imaging and characterisation of subsurface solute transport using electrical resistivity tomography (ERT) and equivalent transport models. Journal of Hydrology, 267:125-146.

A. Kemna, A. Binley, F. Day-Lewis, A. Englert, B. Tezkan, J. Vanderborght, H. Vereecken, and P. Winship. 2006. Applied Hydrogeophysics, volume 71 of Earth and Environmental Science, chapter Solute transport processes, pages 117-159. Springer Netherlands. 
R. Ketelsen and R. Kirsch. 2004. Zur geophysikalischen erkundung van versalzungszonen im grundwasser. Meyniana, 56:21-45.

K. Kipp. 1987. Hst3d, a computer code for simulation of heat and solute transport in three-dimensional ground-water flow systems. Report 86-4095, U. S. Geol. Surv. Water-Resour. Inv.

R. Kirsch. 2006. Groundwater Geophysics - a tool for Hydrogeology. Springer, New York.

J. K. Koestel, A. Kemna, M. Javaux, A. Binley, and H. Vereecken. 2008. Quantitative imaging of solute transport in an unsaturated and undisturbed soil monolith with 3D ERT and TDR. Water Resour. Res., page in press.

M. Koukadaki, G. Karatzas, M. Papadopoulou, and A. Vafidis. 2007. Identification of the saline zone in a coastal aquifer using electrical tomography data and simulation. Journal Water Resources Management, 21:1881-1898.

D. LaBrecque, M. Miletto, W. Daily, A. Ramirez, and E. Owen. 1996. The effects of noise on Occam's inversion of resistivity tomography data. Geophysics, 61:538-548.

L. Lebbe. 1999. Parameter identification in fresh-saltwater flow based on borehole resistivities and freshwater head data. Advances in Water Resources, 22:791-806.

N. Linde, J. Chen, M. Kowalsky, and S. Hubbard. 2006. Applied hydrogeophysics, volume 71 of Earth and Environmental Science, chapter Hydrogeophysical parameter estimation approaches for field scale characterization, pages 9-44. Springer Netherlands.

M.H. Loke and R.D. Barker. 1996. Rapid least-squares inversion of apparent resistivity pseudosections using a quasi-newton method. Geophysical Prospecting, 44:131-152.

M.C. Looms, A. Binley, J. Karsten, N. Lars, and M.H. Thomas. 2008. Identifying unsaturated hydraulic parameters using an integrated data fusion approach on cross-borehole geophysical data. Vadose Zone J, $7: 238-248$.

M. Meju. 1994. Geophysical Data Analysis: Understanding Inverse Problem Theory and Practice, volume 6 of SEG Course Notes Series. Society of Exploration Geophysicists, Tulsa, Oklahoma.

A. Melloul and M. Collin. 2006. Hydrogeological changes in coastal aquifers due to sea level rise. Ocean and Coastal Management, 49:281-297. 
H.A. Michael, A.E. Mulligan, and C.F. Harvey. 2005. Seasonal oscillations in water exchange between aquifers and the coastal ocean. Nature, 436:1145-1148.

F. Nguyen, A. Kemna, A. Antonsson, P. Engesgaard, O. Kuras, R. Ogilvy, J. Gisbert, S. Jorreto, and I. Frances-Hererra. 2007. Characterization of saltwater intrusion using electrical imaging: numerical simulation and field study. In AGU Join Meeting, Acapulco, Mexico. Plubished abstract in proceeding.

R D. Ogilvy, O. Kuras, P I. Meldrum, P B. Wilkinson, J. E. Chambers, M. Sen, J. Gisbert, S. Jorreto, I. Frances, A. Pulido-Bosch, and P. Tsourlos. 2009. Automated time-Lapse Electrical Resistivity Tomography (ALERT) for monitoring coastal aquifers. Near Surface Geophysics Journal, Special issue on hydrogeophysics, in press: $\mathrm{xxx}-\mathrm{xxx}$.

R.D. Ogilvy, O. Kuras, P.I. Meldrum, P.B. Wilkinson, J.E. Chambers, J. Gisbert, S. Joretto, A. PulidoBosch, A. Kemna, Nguyen F., and P. Tsourlos. 2007. Automated monitoring of coastal aquifers with electrical resistivity tomography. In Proceedings TIAC'07 International Conference on Technology of Seawater Intrusion in Coastal Aquifers, Almeria, Spain.

G.H.P. Oude Essink. 2003. Coastal Aquifer Management-Monitoring, Modeling and Recent Practices, chapter Modelling 3D density dependent groundwater flow at the Island of Texel, The Netherlands, pages 77-94. Lewis Publishers, Florida, USA.

A. Panday, P.S. Huyakorn, J.B. Robertson, and B. McGurk. 1993. A density-dependent flow and transport analysis of the effects of groundwater development in a freshwater lens of limited areal extent: the Geneva area (Florida, U.S.A.) case study. . J. Contam. Hydrol., 12:329-354.

R.L. Parker. 1994. Geophysical inverse theory. Princeton University Press.

A. Pulido-Bosch, F. Sanchez-Martos, J.L. Martinez-Vidal, and F. Navarrete. 1992. Groundwater problems in a semiarid area. lower andarax river, almeria, spain. Environ. Geol., 20:195-205.

A. Pulido-Bosch, P. Pulido-Leboeuf, and J. Gisbert. 2004. Pumping seawater from coastal aquifers for supplying desalination plants. Geologica Acta, 2:97-101.

P. Pulido-Leboeuf. 2004. Seawater intrusion and associated processes in a small coastal complex aquifer (Castell de Ferro, Spain). Applied Geochemistry, 19:1517-1527. 
D. T. Purvance and R. R. Andricevic. 2000. Geoelectric characterization of the hydraulic conductivity field and its spatial structure at variable scales. Water Resour. Res., 36:2915-2924.

A.L. Ramirez, W.D. Daily, and R.L. Newmark. 1995. Electrical resistance tomography for steam injection monitoring and process control. Journal of Environmental and Engineering Geophysics, pages 39-51.

T.E. Reily and A.S. Goodman. 1987. Analysis of saltwater upconing beneath a pumping well. Journal of Hydrology, 89:169-204.

A. Revil and Glover P.W.J. 1998. Nature of surface electrical conductivity in natural sands, sandstones, and clays. Geophysical Research Letters, 25:691-694.

Y. Rubin and S. S. Hubbard. 2005. Hydrogeophysics. Springer, Dordrecht, The Netherlands.

E. Sanz and C.I. Voss. 2006. Inverse modeling for seawater intrusion in coastal aquifers: Insights about parameter sensitivities, variances, correlations and estimation procedures derived from the Henry problem. Advances in Water Resources, 29:439-457.

V. Shtivelman and M. Goldman. 2000. Integration of shallow reflection seismics and time domain electromagnetics for detailed study of the coastal aquifer in the nitzanim area of israel. Journal of Applied Geophysics, 44:197-215.

L. Slater, A.M. Binley, W. Daily, and R. Johnson. 2000. Cross-hole electrical imaging of a controlled saline tracer injection. Journal of Applied Geophysics, 44:85-102.

E. A. Sudicky. 1989. The Laplace transform Galerkin technique - a time-continuous finite-element theory and application to mass-transport in groundwater. Water Resources Research, 25:1833-1846.

J. Tronicke and K. Holliger. 2005. Quantitative integration of hydrogeophysical data: Conditional geostatistical simulation for characterizing heterogeneous alluvial aquifers. Geophysics, 70:H1H10.

P.I. Tsourlos, R.D. Ogilvy, and C. Papazachos. 2004. Borehole-to-surface ert inversion. In 10th meeting of the EEGS, Utrecht, The Netherlands.

N. Van Cauwenbergh, P. Didrik, T. Amaury, and Vanclooster M. April 2006. Water management in the Andarax river, Almeria - part ii: decision support system. In AquainMed, editor, International Conference "El Agua Subterranea en Paises Mediterraneos, Malaga, Spain,. 
J. Vanderborght, A. Kemna, H. Hardelauf, and H. Vereecken. 2005. Potential of electrical resistivity tomography to infer aquifer transport characteristics from tracer studies: A synthetic case study. Water Resour. Res., 41:W06013.

H. Vereecken, A. Binley, G. Cassiani, A. Revil, and K. Titov. 2006. Applied Hydrogeophysics. Springer, Dordrecht, The Netherlands.

C.I. Voss and W.R. Souza. 1987. Variably density flow and solute transport simulation of regional aquifers containing a narrow fresh-water saltwater transition zone. Water Resour. Res., 23:1851-1866.

M.H. Waxman and L.J.M. Smits. 1968. Electrical conductivities in oil-bearing shaly sands. Soc. Petr. Eng. $J ., 8: 107-122$.

S.R. Wilson, M. Ingham, and J.A. McConchie. 2006. The applicability of earth resisitivity methods for saline interface definition. Journal of hydrology, 316:301-312.

C.H. Yang, L.T. Tong, and C.F. Huang. 1999. Combined application of dc and tem to sea-water intrusion mapping. Geophysics, 64:417-425. 
${ }_{638} 1$ Parameters for the density-dependent flow and transport model. 
1 Ghyben-Herzberg analytical seawater intrusion model (Bear et al., 1999; Guo and Jiao, 2007) with (a) higher and (b) lower inflow $q . h$ is the water head above sea level. Note that in real situation, the interface is diffuse and not sharp as represented here for simplicity.

2 Domain geometry and boundary conditions (BC) for the finite-difference seawater intrusion model (not to scale). Pressure-depth curves are shown on both sea and inland sides.

3 Petrophysical relationships between bulk electrical conductivity $\left(\sigma_{b}\right)$ and water conductivity $\left(\sigma_{w}\right)$ for different samples of the Almeria test site. $F^{\prime}$ denotes the effective formation factor computed from fitting the data using equation (3.9) (neglecting the surface conduction term $b$ ).

4 Conversion from simulated mass fraction distribution (a) to electrical resistivity model (c) using the petrophysical relationships given in equations (3.6) and (3.9). ERT imaging results (d) and ERT-derived mass fraction (b) (using equations (3.6) and (3.9)).

5 Illustration of the behavior of ERT-derived mass fraction versus true mass fraction (bottom) with increasing depth. The two bottom plots were extracted from boxes A and B in the upper image, showing the spatial variation of the cumulative sensitivity as defined by equation 2.5 .

6 Comparison between true and ERT recovered mass fraction isolines for different hydrogeological simulations where the transverse dispersivity varies.

7 Influence of the cumulative sensitivity distribution on the true (dashed red line) and recovered (solid red line) mass fraction 0.01 isoline for a layered model (the layer is indicated by the solid black lines). The sensitivity is clipped for values smaller than $10 \mathrm{e}-5$ of the maximum value. The difference in sensitivity arises from different electrical contrasts corresponding to brackish (top) and fresh (bottom) upstream water.

8 Spain is shown on the upper left map, the Province of Andalusia (where the field site is located) is highlighted. The image map shows the location of the Andarax river bed (blue line), where the ERT profile is located and positions of the deep boreholes B320, B520 and B1320. The borehole 
numbers correspond to the horizontal distance along the ERT profile. Two pictures (right) show the installation of the electrodes on the PVC casing of the deep boreholes.

9 Histograms of relative resistance errors for the manual surface dataset (inferred from stacking (dark blue) and normal-reciprocal analysis (red)) and the permanent surface-to-hole dataset (inferred from stacking (light blue)). The inner box shows that the relative histograms for the surface datasets are similar.

10 Field ERT results (a) and derived mass fraction distribution (b). The black lines graphs in figure b show the normalized water electrical conductivity logs at scale for boreholes B320, B820, and B1320 located on figure 8. The dashed line indicates the separation between two domains of different Archie's formation factors (see figure 3).

11 Wells B320 (a) and B820 (b) information (see figure 8). For each subplots, from left to right: in situ formation factors computed from in-hole bulk resistivity and water electrical resistivity (dot-dash line correspond the laboratory formation factor; see figure 3), water electrical resistivity, in-hole ERT (green line) and surface ERT (red dots) bulk electrical resistivity logs, and geology.

12 Surface imaging result (b) and surface-to-borehole imaging result (a) at the site of Almeria. The red rectangle in (a) shows the position of the surface-to-borehole image. 
TABLe 1. Parameters for the density-dependent flow and transport model.

\begin{tabular}{ll}
\hline Parameter & Value \\
\hline Horizontal hydraulic conductivity $K_{h}$ & $100 \mathrm{~m} / \mathrm{d}$ \\
Vertical hydraulic conductivity $K_{v}$ & $1 \mathrm{~m} / \mathrm{d}$ \\
Permeability $k$ & $1.2 \mathrm{e}-10 \mathrm{~m}^{2}$ \\
Effective porosity $\epsilon$ & 0.30 \\
Horizontal dispersivity $\alpha_{L}$ & $10 \mathrm{~m}$ \\
Transversal dispersivity $\alpha_{T}$ & $0.5 \mathrm{~m}$ \\
Freshwater density $\rho_{f}$ & $1000 \mathrm{~kg} / \mathrm{m}^{3}$ \\
Seawater density $\rho_{s}$ & $1025 \mathrm{~kg} / \mathrm{m}^{3}$ \\
Seawater mass fraction $\omega$ & 0.0357 \\
Diffusion coefficient $D_{m}$ & $0 \mathrm{~m}^{2} / \mathrm{s}$ \\
Viscosity $\mu$ & $1.0 \mathrm{e}-3 \mathrm{~kg} / \mathrm{ms}$ \\
Fluid compressibility & $0 \mathrm{~kg} / \mathrm{ms}^{2}$ \\
Matrix compressibility & $0 \mathrm{~kg} / \mathrm{ms}^{2}$ \\
\hline
\end{tabular}




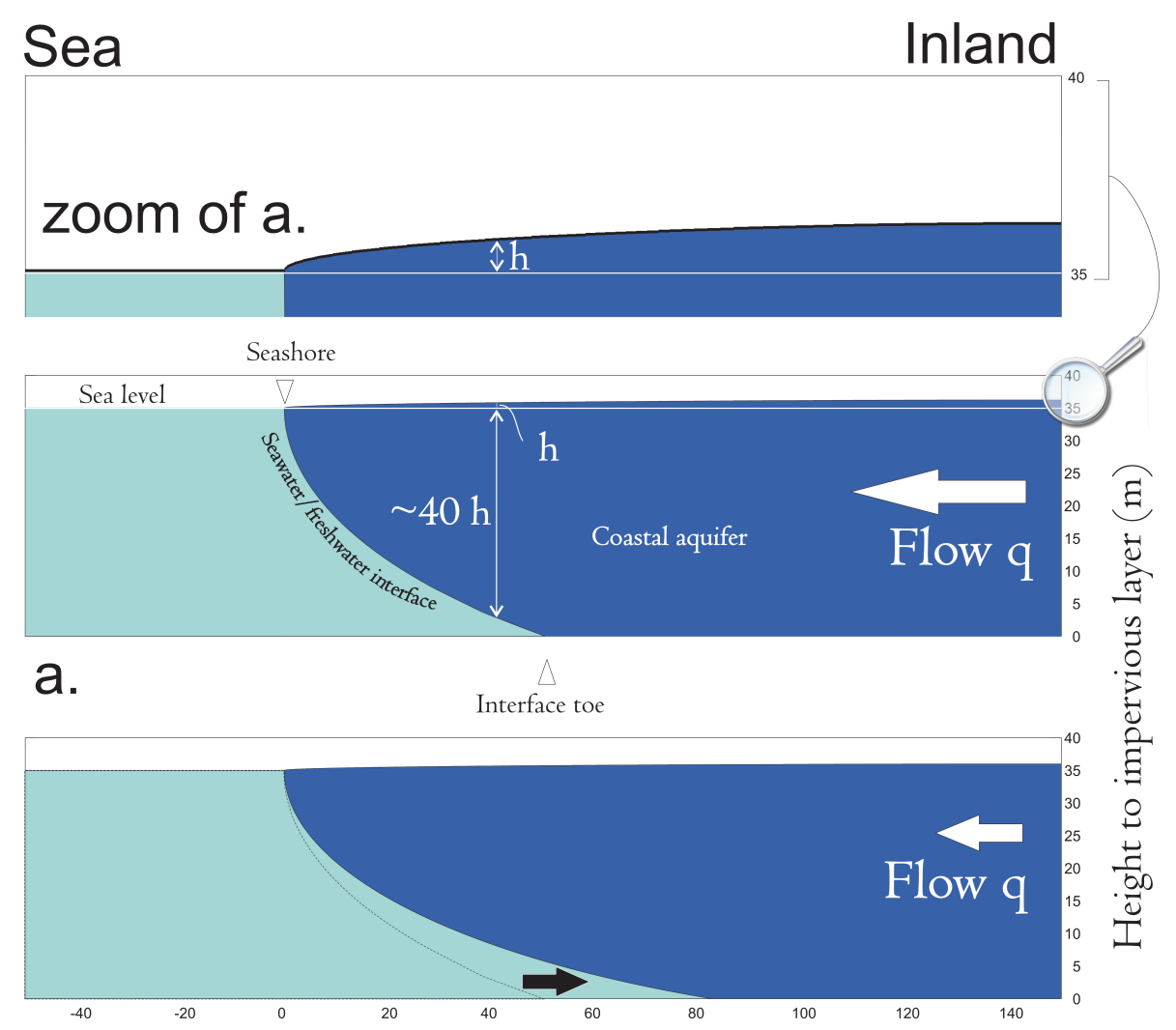

b.

Distance from shoreline ( $\mathrm{m}$ )

Figure 1. Ghyben-Herzberg analytical seawater intrusion model (Bear et al., 1999; Guo and Jiao, 2007) with (a) higher and (b) lower inflow $q . h$ is the water head above sea level. Note that in real situation, the interface is diffuse and not sharp as represented here for simplicity. 


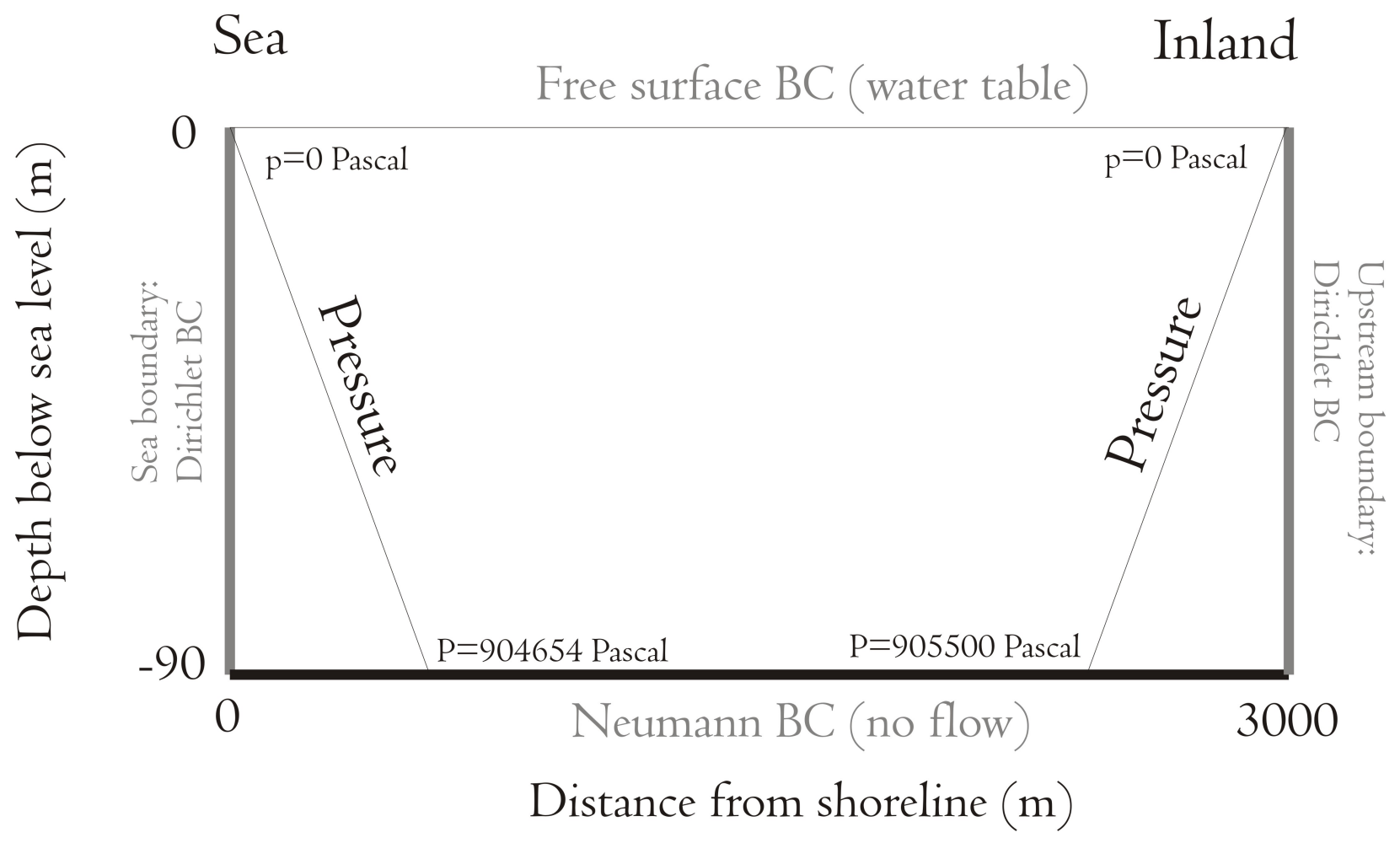

Figure 2. Domain geometry and boundary conditions (BC) for the finite-difference seawater intrusion model (not to scale). Pressure-depth curves are shown on both sea and inland sides. 


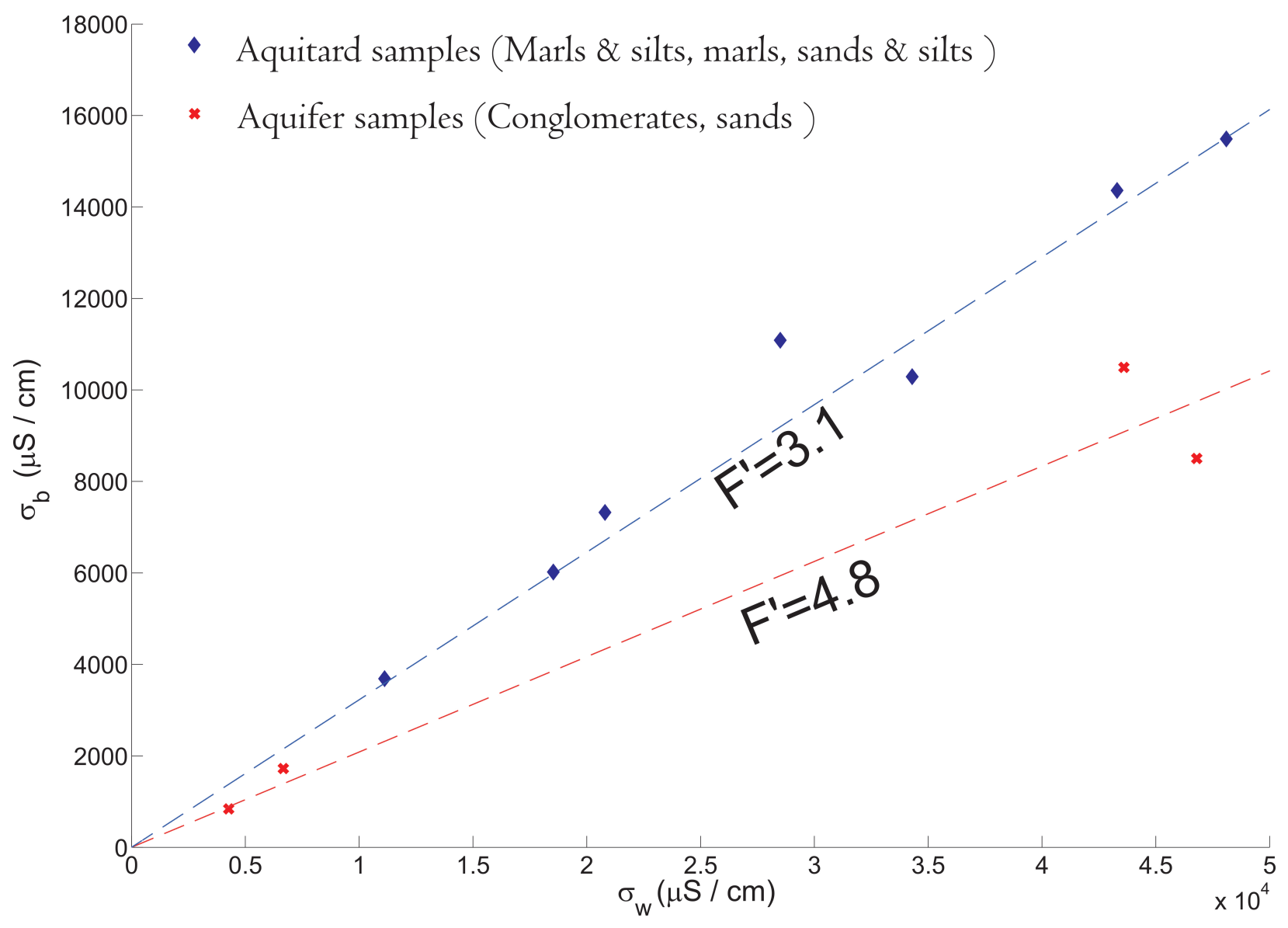

Figure 3. Petrophysical relationships between bulk electrical conductivity $\left(\sigma_{b}\right)$ and water conductivity $\left(\sigma_{w}\right)$ for different samples of the Almeria test site. $F^{\prime}$ denotes the effective formation factor computed from fitting the data using equation (3.9) (neglecting the surface conduction term $b$ ). 


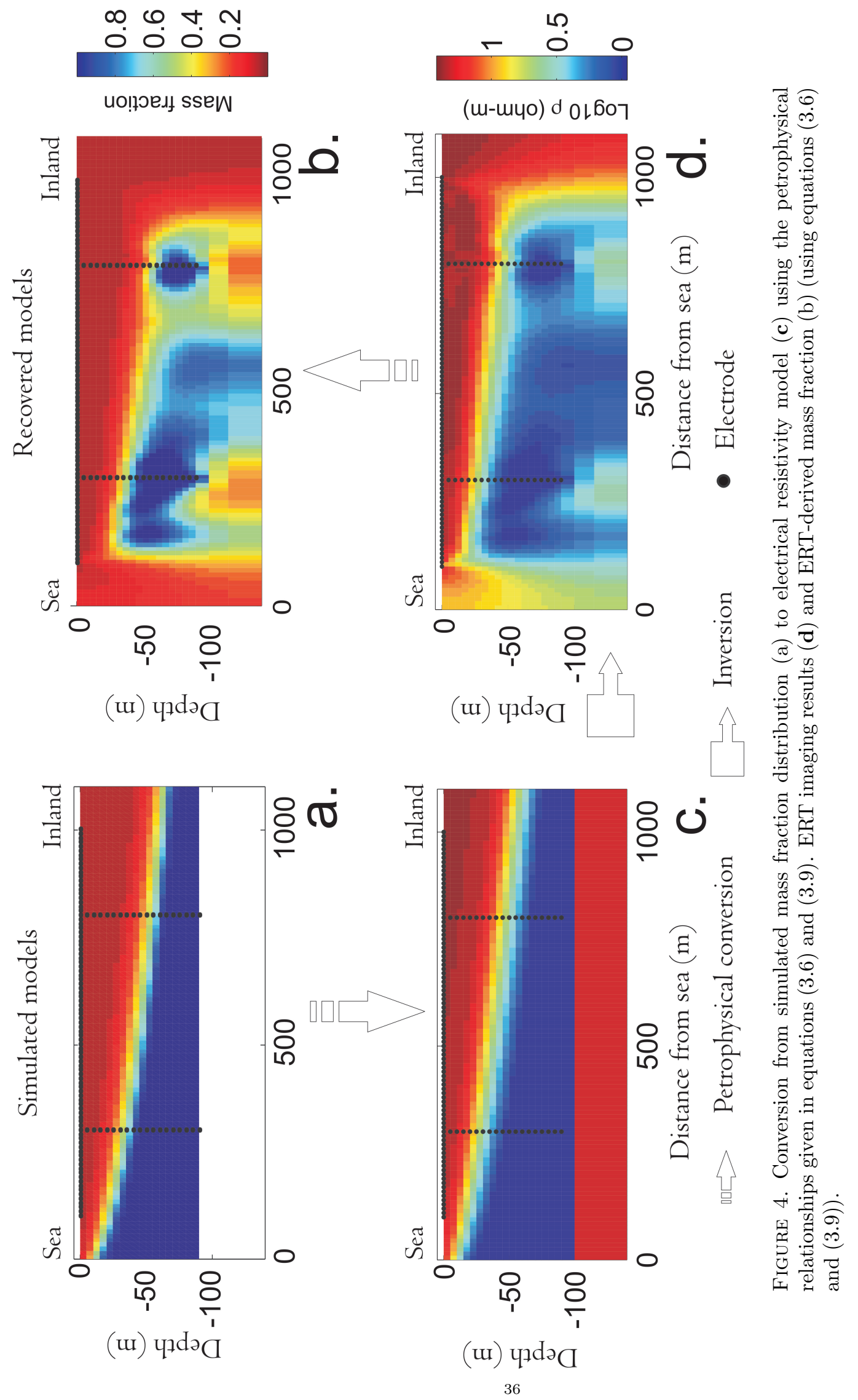



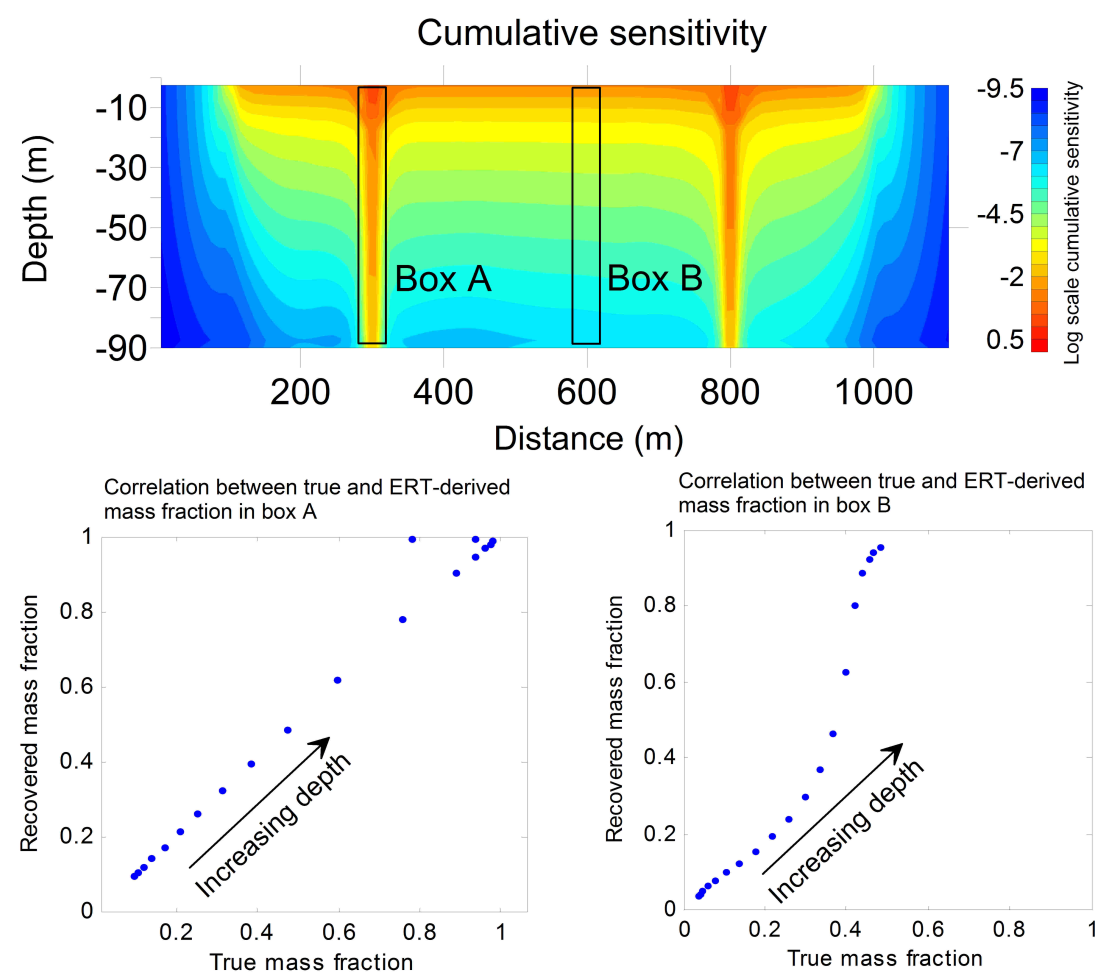

FIGURE 5. Illustration of the behavior of ERT-derived mass fraction versus true mass fraction (bottom) with increasing depth. The two bottom plots were extracted from boxes A and B in the upper image, showing the spatial variation of the cumulative sensitivity as defined by equation 2.5 . 


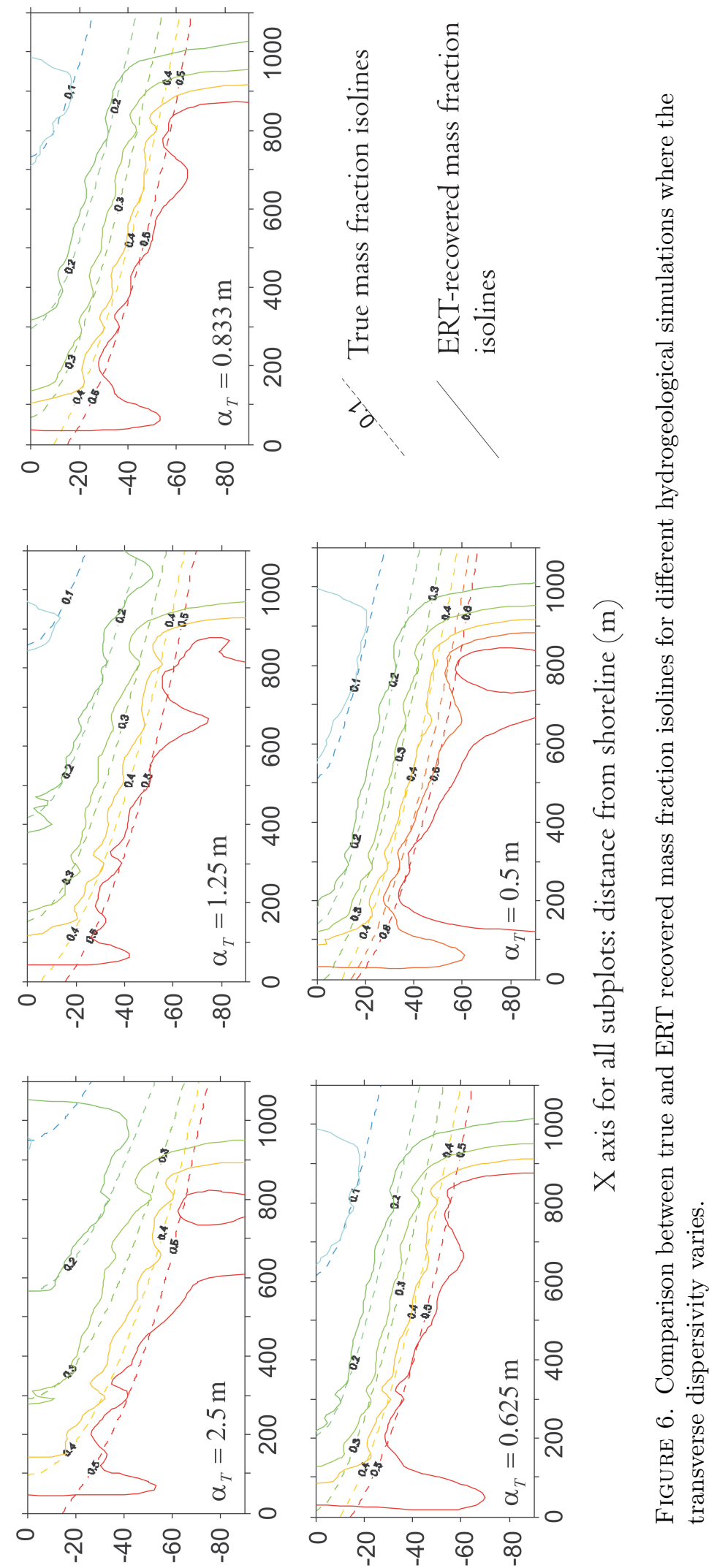

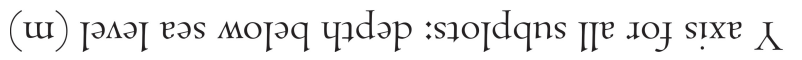



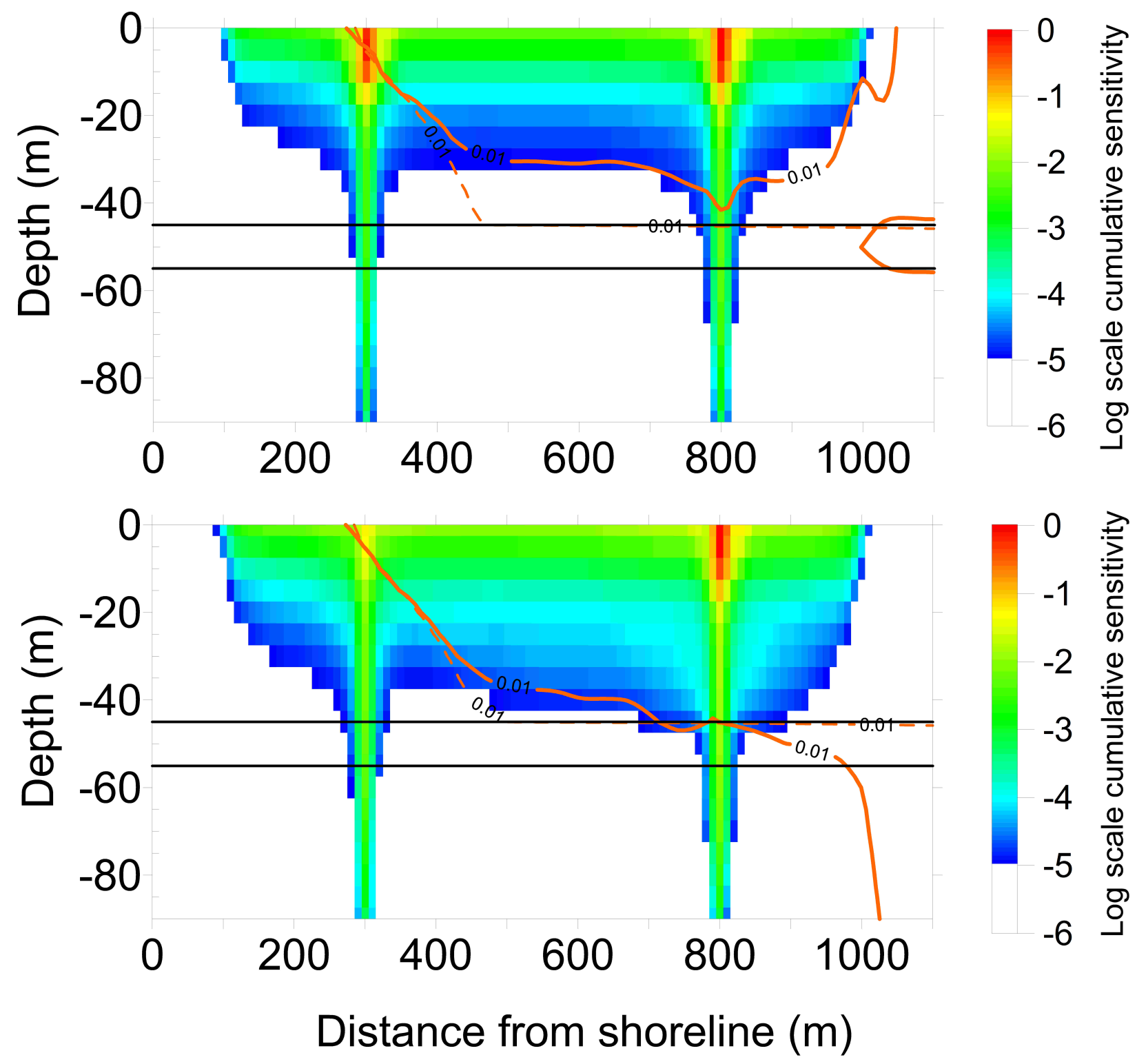

FIGURE 7. Influence of the cumulative sensitivity distribution on the true (dashed red line) and recovered (solid red line) mass fraction 0.01 isoline for a layered model (the layer is indicated by the solid black lines). The sensitivity is clipped for values smaller than $10 \mathrm{e}-5$ of the maximum value. The difference in sensitivity arises from different electrical contrasts corresponding to brackish (top) and fresh (bottom) upstream water. 


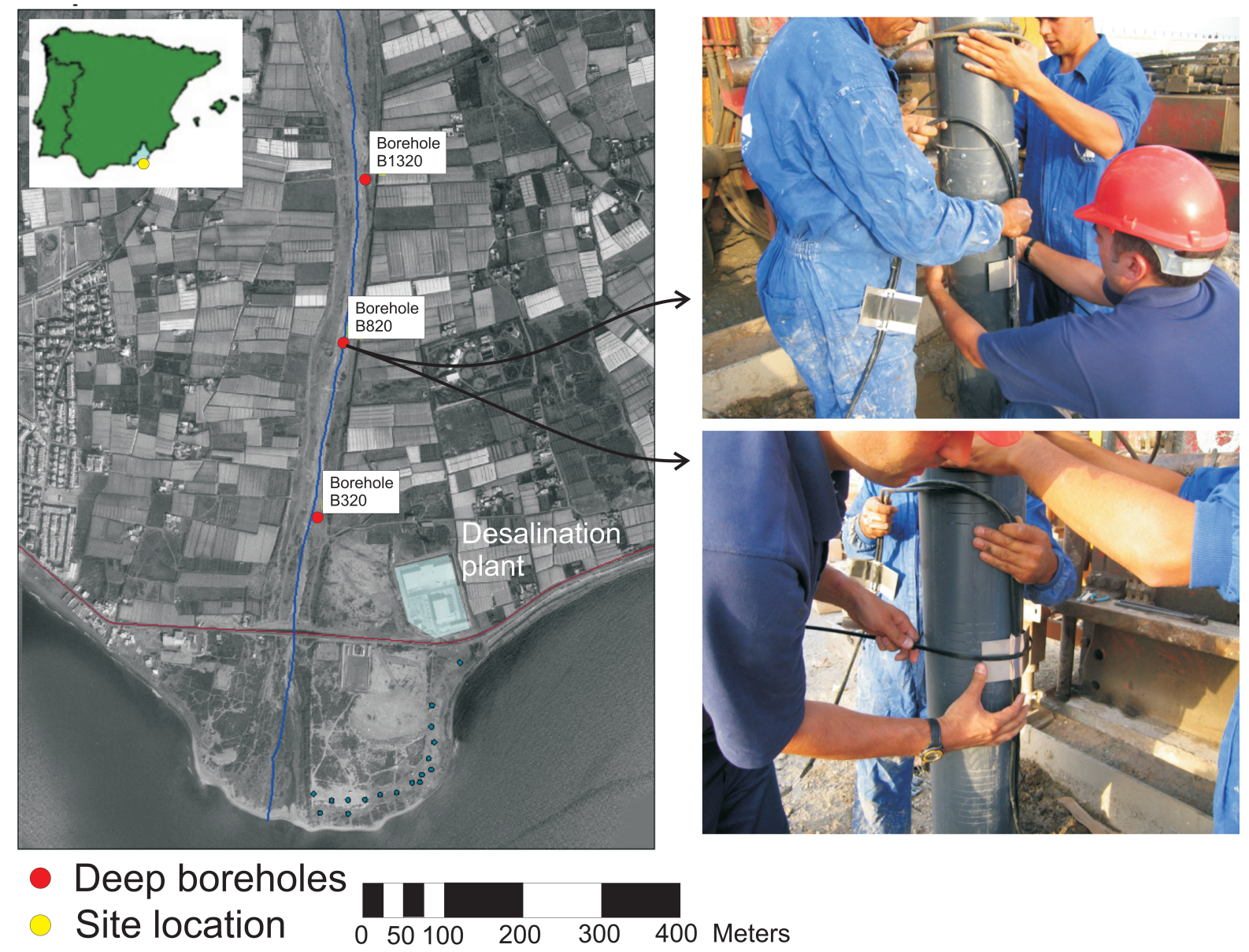

FiguRE 8. Spain is shown on the upper left map, the Province of Andalusia (where the field site is located) is highlighted. The image map shows the location of the Andarax river bed (blue line), where the ERT profile is located and positions of the deep boreholes B320, B520 and B1320. The borehole numbers correspond to the horizontal distance along the ERT profile. Two pictures (right) show the installation of the electrodes on the PVC casing of the deep boreholes. 


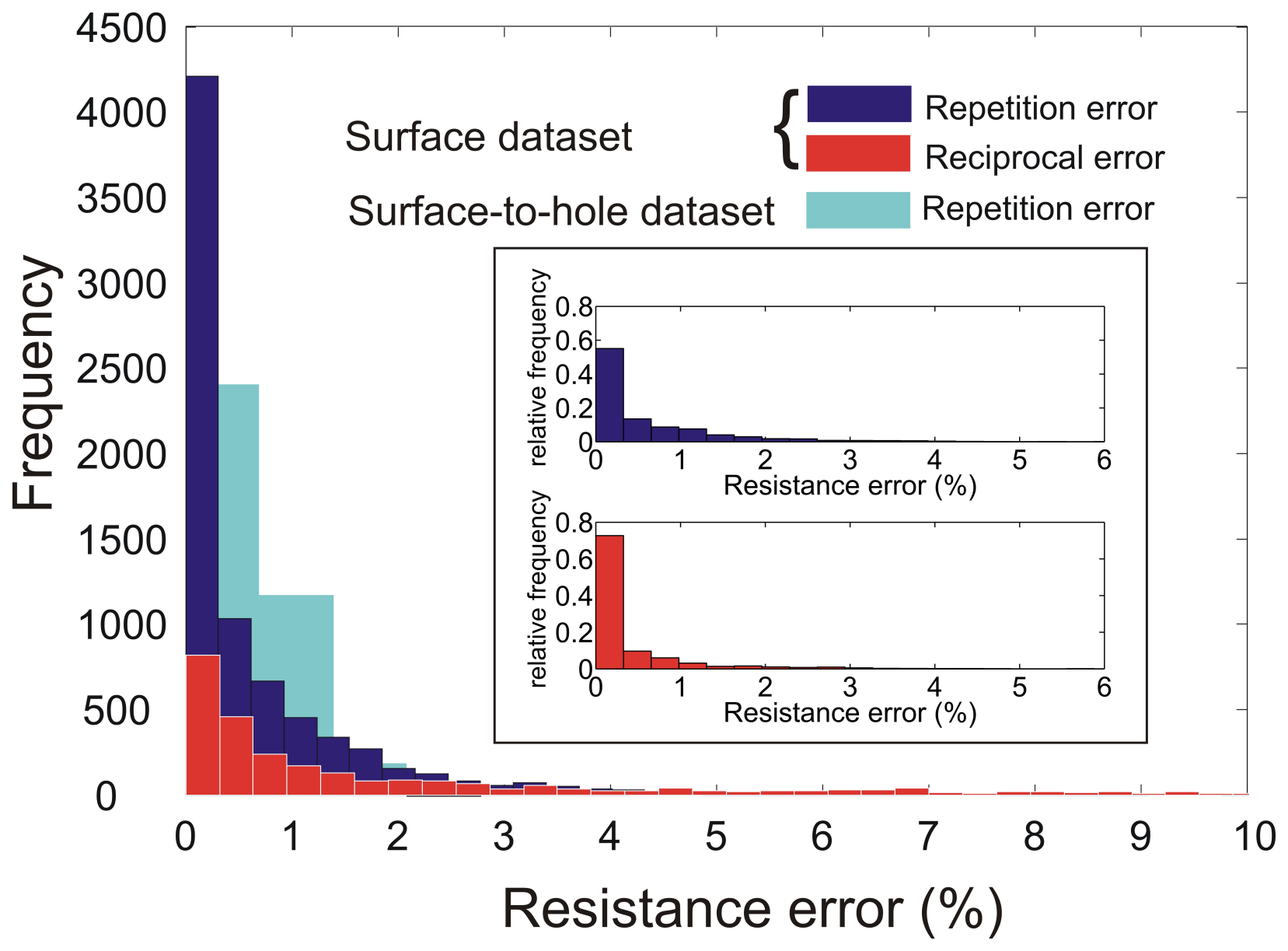

FIGURE 9. Histograms of relative resistance errors for the manual surface dataset (inferred from stacking (dark blue) and normal-reciprocal analysis (red)) and the permanent surfaceto-hole dataset (inferred from stacking (light blue)). The inner box shows that the relative histograms for the surface datasets are similar. 

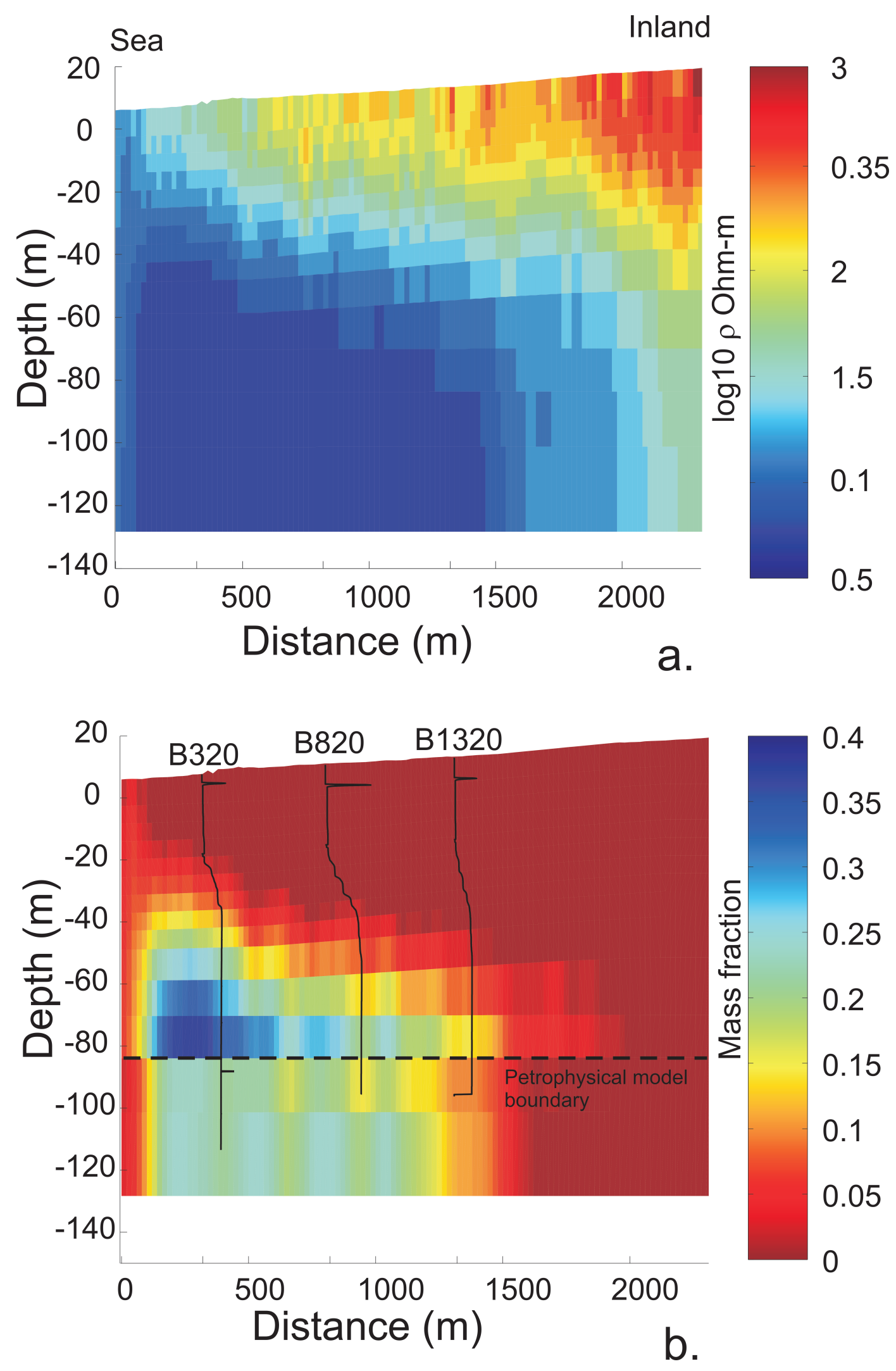

FiguRE 10. Field ERT results (a) and derived mass fraction distribution (b). The black lines graphs in figure b show the normalized water electrical conductivity logs at scale for boreholes B320, B820, and B1320 located on figure 8. The dashed line indicates the separation between two domains of different Archie's formation factors (see figure 3). 

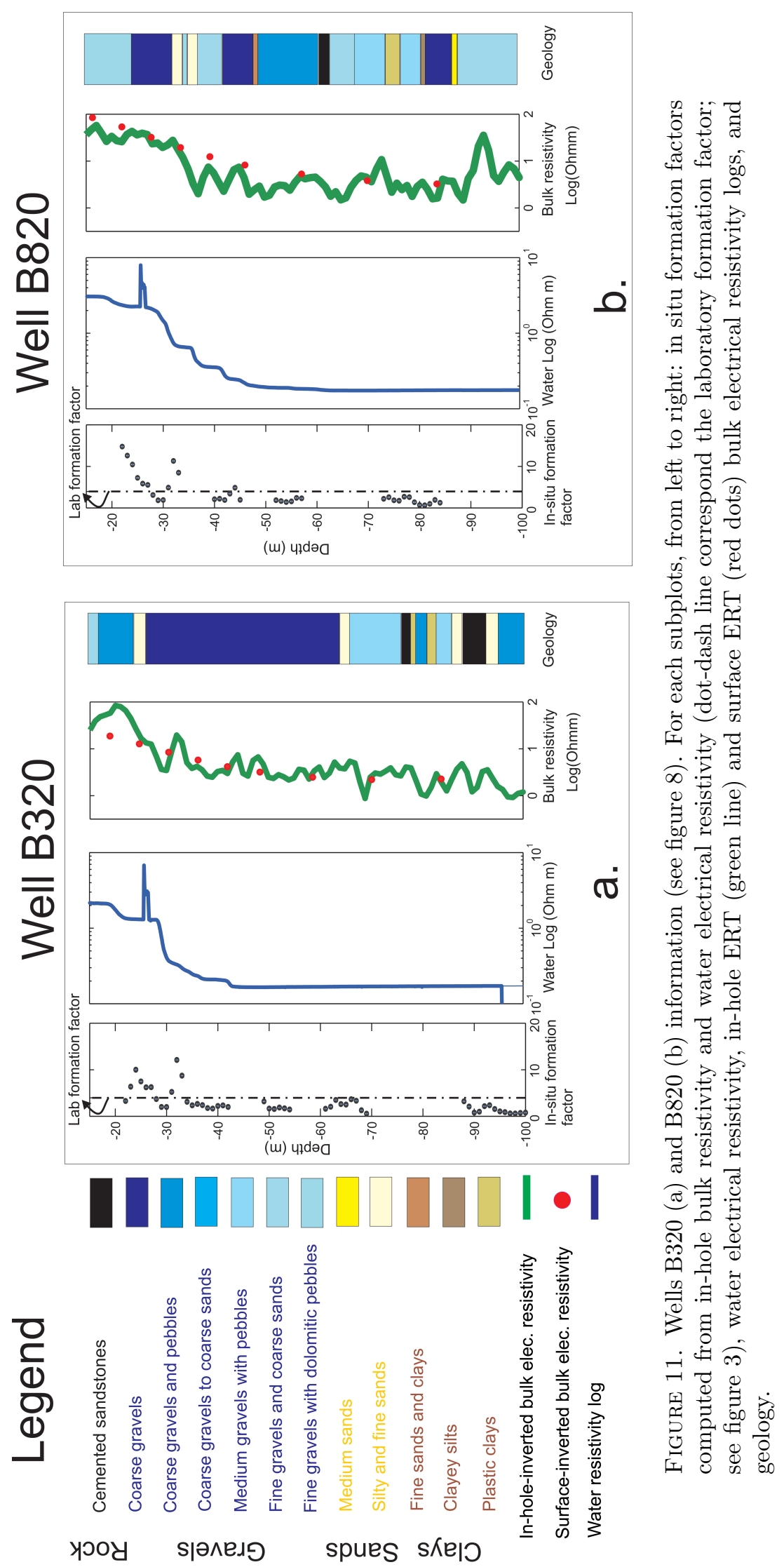


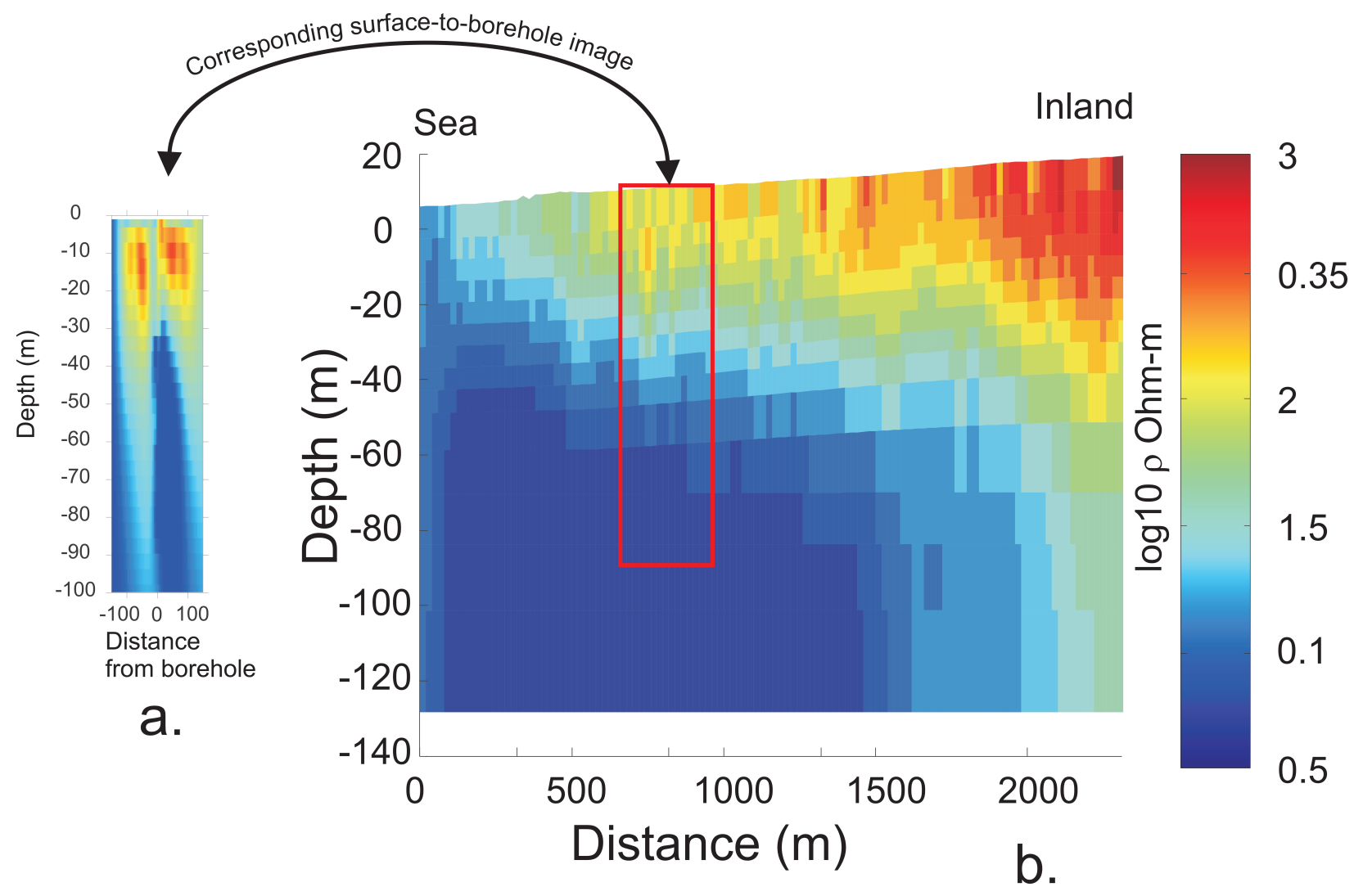

FiguRE 12. Surface imaging result (b) and surface-to-borehole imaging result (a) at the site of Almeria. The red rectangle in (a) shows the position of the surface-to-borehole image. 